\title{
Tropical Rainfall Distributions Determined Using TRMM Combined with other Satellite and Raingauge Information
}

\author{
Robert F. Adler ${ }^{1}$, George J. Huffman ${ }^{2}$, David T. Bolvin ${ }^{2}$, \\ Scott Curtis $^{3}$, and Eric J. Nelkin ${ }^{2}$ \\ 1:NASA/GSFC Laboratory for Atmospheres \\ 2:NASA/GSFC Laboratory for Atmospheres and \\ Science Systems and Applications, Inc. \\ 3:NASA/GSFC Laboratory for Atmospheres and \\ U. Maryland at Baltimore County/Joint Center \\ for Earth Systems Technology
}

24 September 1999

Submitted to $J$. Appl. Meteor.

\footnotetext{
Corresponding author address: Robert F. Adler, Code 912, NASA/Goddard Space Flight Center, Greenbelt, MD 20771, USA

E-mail: adler@agnes.gsfc.nasa.gov
} 


\title{
Tropical Rainfall Distributions Determined Using TRMM Combined with other Satellite and Raingauge Information
}

\begin{abstract}
A technique is described to use Tropical Rain Measuring Mission (TRMM) combined radar/radiometer information to adjust geosynchronous infrared satellite data (the TRMM Adjusted GOES Precipitation Index, or TRMM AGPI). The AGPI is then merged with rain gauge information (mostly over land; the TRMM merged product) to provide finescale ( $1^{\circ}$ latitude/longitude) pentad and monthly analyses, respectively. The TRMM merged estimates are $10 \%$ higher than those from the Global Precipitation Climatology Project (GPCP) when integrated over the tropical oceans $\left(37^{\circ} \mathrm{N}-\mathrm{S}\right)$ for 1998 , with $20 \%$ differences noted in the most heavily raining areas. In the dry subtropics the TRMM values are smaller than the GPCP estimates. The TRMM merged-product tropical-mean estimates for 1998 are $3.3 \mathrm{~mm} \mathrm{day}^{-1}$ over ocean and $3.1 \mathrm{~mm}^{-1 a y}{ }^{-1}$ over land and ocean combined. Regional differences are noted between the western and eastern Pacific Ocean maxima when TRMM and GPCP are compared. In the eastern Pacific rain maximum the TRMM and GPCP mean values are nearly equal, very different from the other tropical rainy areas where TRMM merged-product estimates are higher. This regional difference may indicate that TRMM is better at taking into account the vertical structure of the rain systems and the difference in structure between the western and eastern (shallower) Pacific convection.

Comparisons of these TRMM merged analysis estimates with surface data sets shows varied results; the bias is near zero when compared to western Pacific Ocean atoll raingauge data, but significantly positive compared to Kwajalein radar estimates (adjusted by rain gauges). Over land the TRMM estimates also show a significant positive bias. The inclusion of gauge information in the final merged product significantly reduces the bias over land, as expected.

The monthly precipitation patterns produced by the TRMM merged data process clearly show the evolution of the ENSO tropical precipitation pattern from early 1998 (El Niño) through early 1999 (La Niña) and beyond. The El Niño minus La Niña difference map shows the eastern Pacific maximum, the maritime continent minima and other tropical and mid-latitude features. The differences in the Pacific are very similar to those detected by the GPCP analyses. However, summing the El Niño minus La Niña differences over the global tropical oceans yields divergent answers from TRMM, GPCP and other estimates. This emphasizes the need for additional validation and analysis before it is feasible to understand the relations between global precipitation anomalies and Pacific Ocean ENSO temperature changes.
\end{abstract}


Index (GPI; Arkin and Meisner 1987) assigns a single rainrate to all pixels colder than a specified temperature threshold. Adler et al. $(1993,1994)$ showed that biases in the GPI could be minimized by adjusting the GPI rain rate in space and time to some other sparse, but more accurate estimate. In TRMM this Adjusted GPI (AGPI) is produced by using cases of (nearly) coincident TRMM Combined Instrument (TCI; the combined TMI and PR algorithm, Haddad et al. 1997) and VIRS IR data to compute a time- and spacevarying IR - rain rate relationship that matches (i.e., is "adjusted" to) the TCI-inferred rain rate. The use of (nearly) coincident TCI and VIRS IR data prevents sampling issues from affecting the derived relations. The adjusted IR - rain rate relationships are then applied to the full geo-IR data to take advantage of their superior time sampling. To the extent that the TCI estimates are unbiased, the bias of the AGPI ought to be small as well. The AGPI is produced operationally in TRMM as product $3 \mathrm{~B}-42$ by estimating the adjustment coefficients for calendar months on a $1^{\circ} \times 1^{\circ}$ lat./long. grid, then calculating daily AGPI accumulations from the three hourly geo-IR data on the same grid. An example month of the key fields for AGPI is shown in the top three panels of Fig. 1. The TRMM TCI field in the top panel is relatively noisy due to the limited sampling of TRMM. The GPI field in the second panel is limited by the characteristics of the IRbased algorithm, but contains eight samples per day from the geosynchronous satellites. The third panel shows the result of applying the adjustment coefficients derived from the TCI/VIRS comparison to the full geosynchronous data set. This TRMM AGPI has the local bias of the TRMM TCI estimate and the high-frequency sampling of the geo-IR data.

The monthly TRMM and Other Data merged estimate is produced by merging the AGPI with information from rain gauges. The gauge analysis (the fourth panel in Fig. 1) used in this procedure is from the GPCP (Rudolf 1993). The merger is computed in two steps, following Huffman et al. (1997). First, the satellite estimate is adjusted to the large-area gauge information. For each grid box over land the AGPI estimate is multiplied by the ratio of the large-scale ( $5 \times 5$ grid-box) average gauge analysis to the large-scale average of the AGPI estimate. Alternatively, in low-precipitation areas the difference in the large-scale averages is added to the AGPI value when the averaged gauge exceeds the averaged AGPI. This procedure keeps the bias of the merged product close to the (presumably small) bias of the gauge analysis on a regional scale, even while allowing the AGPI estimate to provide important local detail. Second, the gauge-adjusted AGPI estimate and the gauge analysis are linearly combined with inverse-error-variance weighting. The errors employed in the combination are estimates of the (spatially varying) root-mean-square random error for each field, following Huffman (1997). The merged satellite/gauge product is produced operationally in TRMM as product $3 \mathrm{~B}-43$ for calendar months on a $1^{\circ} \times 1^{\circ}$ lat./long. grid. The bottom panel in Fig. 1 contains the example of the final, merged product. Over the ocean the results are identical to that of the third panel, with adjustments over land due to the influence of the rain gauges.

In the following discussions the focus will be on the analysis of the final merged product (fields of the type shown in the bottom panel of the example), although some comparisons with surface-based estimates will utilize the satellite-only AGPI product (middle panel). A key part of the following analysis is a comparison with the standard merged product produced by the Global Precipitation Climatology Project (GPCP). The 
The mean $10 \%$ difference over the ocean is not a constant, but varies regionally. Fig. 2 shows that the TRMM merged analysis is significantly higher in the western Pacific, especially south of the Equator, and in the eastern Indian Ocean and the eastern portion of the Atlantic ITCZ. From Figs. 2 and 4 TRMM is higher above $30^{\circ} \mathrm{N}$, especially east of Japan and the U.S. coasts. In the Southern Hemisphere mid-latitudes, TRMM and GPCP means are nearly identical (Fig. 4), but TRMM has larger values just southeast of South Africa, Australia, and South America, with GPCP being larger to the east of those three locations. These mid-latitude variations point to a possible difference in vertical structure from coastal waters (deeper convection) to the open ocean (shallower) that might be better detected by TRMM.

We investigated regional variations further by taking averages for 1998 over some smaller areas. Fig. 5 displays locations of the seven numbered averaging boxes and the results are shown in Table 2. Boxes 2 and 3 in the western Pacific Ocean ITCZ and SPCZ precipitation maxima display TRMM merged estimates that are significantly higher $(>20 \%)$ than the GPCP estimates. However, box 4 in the Eastern Pacific Ocean ITCZ has a very small $(\sim 4 \%)$ mean difference between the two. This East Pacific/West Pacific difference is probably related to the mean vertical structure of the rain systems, with those in the Eastern Pacific being shallower. The TRMM estimates, which include information from the TRMM radar, may more accurately reflect the impact of the vertical structure on the surface rain estimate. Boxes 1 and 5 in the eastern Indian Ocean and Atlantic ITCZ show intermediate ratios, perhaps corresponding to somewhat intermediate cloud heights. For the more mid-latitude boxes just to the east of Asia and South America the TRMM and GPCP estimates are close to each other with TRMM being slightly higher. These regional variations in the differences should be the focus of research with field experiment data or other information to determine if the TRMM estimates are better able to take into account the regional, structural differences in the convection.

The absolute values of the TRMM merged analysis in this study are driven by the TRMM TCI product, which combines information from both the passive microwave and radar instruments (Haddad et al. 1997). This combination of sensor information should be the best TRMM-only absolute rain estimate when it is fully implemented. However, it is worthwhile to compare the TCI with the estimates made with the individual sensors. The four main TRMM-only estimates, two using the passive microwave information, one using the radar alone, and the TCI are shown in zonally-averaged format in Fig. 6. All four estimates agree reasonably well with each other over most of the tropical zone with about a $20 \%$ spread among the four at the peak zonal value. The radar-based estimates are the lowest. Averaged over $20^{\circ} \mathrm{N}$ to $20^{\circ} \mathrm{S}$ the percentage difference drops to $15 \%$. The results therefore indicate that the TCI-based estimates are close to what would be obtained if a different TRMM source were used for computing the TRMM AGPI and merged analysis.

The TRMM merged analysis curve in Fig. 6 is identical to the TRMM AGPI because no gauges are used over water. The TRMM merged curve is based on the TCI, but has the eight times a day sampling from the geosynchronous observations. Since the TCI, or any TRMM-alone product, does not have uniform sampling over the diurnal cycle during 
their relation to SST-based and other ENSO indices. A detailed description of rainfall patterns related to the initiation and evolution of the El Niño/ La Niña of 1997-1999 is given in Curtis et al. (1999).

A finer scale view of the El Niño to La Niña evolution is shown in Fig. 10 using the TRMM daily, $1^{\circ}$ by $1^{\circ}$ latitude-longitude AGPI product. The time-longitude diagram for mean rainfall over $5^{\circ} \mathrm{N}$ to $5^{\circ} \mathrm{S}$ displays the large-scale maxima of the El Niño and La $\mathrm{Niña}$, and the very rapid shift between them from $120^{\circ} \mathrm{W}$ to $120^{\circ} \mathrm{E}$. At smaller scales one can see the eastward propagation of the 30-60 day oscillations during the January-April 1998 period and a strong, very continuous precipitation maximum nearly encircling the globe during May 1998, at the beginning of the La Niña phase. During the La Niña, from June 1998 to January 1999 the predominant propagation direction from the martitime continent across the Pacific and into the Atlantic is from the east. These characteristics and others discernible with finer scale products such as shown in Fig. 10 will help to better understand the evolution of these climate-scale events.

Finally, recent work by Soden (1999) and Robertson (1999, personal communication) has raised important questions about the variation of integrated tropical, oceanic rainfall during ENSO events. Fig. 11 shows such integrated values for a number of estimates during 1997 and 1998, including the TRMM merged product starting in January 1998. The GPCP estimates show a slight rise during El Niño and then a drop during 1998 and into 1999 as the La Niña develops. The TRMM merged analysis shows a very different pattern starting in 1998 with no decrease in integrated precipitation during 1998 and 1999. Even within the TRMM-based products there is a difference. The TMI (TRMM Microwave Imager) product (TRMM product 2A-12) shows a large decrease from early 1998 to early 1999 , while the radar-radiometer product (TCI; TRMM product 3B-31) has no trend during this period. The results from the GPROF algorithm applied to SSM/I data (Kummerow et al. 1996) have a much larger El Niño-centered maximum.

When the analysis is limited to the central and eastern Pacific (the box PAC in Fig. 5), the GPCP and TRMM results agree very well, with the GPROF-SSM/I results still exhibiting a large El Niño maximum (Fig. 12a). The Indian Ocean region (the box IND in Fig. 5) is the main reason for the difference in the integrated tropical trends. GPCP indicates a much smaller maximum in this region during El Niño as compared to the TRMM merged product (Fig. 12b). The basis for these differences in the estimates needs further investigation. The variations among the different products suggest we should be very careful at this time in trying to relate the magnitude of precipitation variations to temperature variations related to ENSO and in global warming.

\section{Comparison of TRMM-based estimates with surface-based estimates of precipitation}

Comparison of TRMM-based estimates of rainfall with independent, surface-based measurements over both ocean and land is a key component of understanding the validity of the TRMM estimates. In this section three surface-based data sets are compared with the TRMM merged estimates. Depending on the case, the comparison is made on a $1^{\circ}$ space scale and on a five day or one month time scale. 
sites (Fig. 16) for pentad periods of TRMM AGPI (TRMM product 3B-42) show a positive bias of the TRMM-based estimates relative to the gauge-adjusted, surface radar estimates. At Houston the bias is about $5 \mathrm{~mm}$ pentad $^{-1}(30 \%)$ and at Melbourne it is 9 $\mathrm{mm}$ pentad ${ }^{-1}(47 \%)$. In order to make a comparison on a wider geographic scale, the GPCP gauge analysis that is used in the final TRMM merged product is used here for comparison with the satellite-only product. A comparison is done over the global tropics for all $1^{\circ}$ boxes in which there are at least two gauges (Fig. 17a). This analysis confirms the positive bias $(28 \%)$ of the TRMM AGPI estimates relative to the gauge analysis.

The final TRMM merged analysis (TRMM product 3B-43) includes GPCP gauge information over land and displays the expected dramatic reduction in variance and bias when it is compared to the GPCP gauge analysis as a check (Fig. 17b). A similar comparison to the Houston and Melbourne Ground Validation data (Fig. 18) shows a similar result, even though there is only a small overlap in the ground validation and GPCP gauge sites. However, especially at Melbourne, the bias is still significant and both the satellite results and the validation data need additional analysis to refine the relations, and lead to improved satellite estimates.

\section{Conclusions}

The technique to use TRMM information to adjust other satellite data and combine with raingauge information over land has been shown useful to derive fine-scale $\left(1^{\circ} \times 1^{\circ}\right.$ latitude/longitude) monthly analyses. Comparison of TRMM merged analysis estimates with surface data sets shows varied results when compared to atoll raingauge data (near zero bias) or Kwajalein radar (adjusted by rain gauges) estimates (significant positive bias). Over land the TRMM estimates also show a significant positive bias. The inclusion of gauge information in the final merged product significantly reduces the bias over land.

The TRMM merged estimates are 10\% higher than those from the Global Precipitation Climatology Project (GPCP) when integrated over the tropical oceans $\left(37^{\circ} \mathrm{N}-\mathrm{S}\right)$ for 1998 , with $20 \%$ differences noted in most heavily raining areas. In the dry subtropics the TRMM values are smaller than the GPCP estimates. The TRMM mergedproduct tropical estimates are $3.3 \mathrm{~mm}^{\text {day }}{ }^{-1}$ over ocean and $3.1 \mathrm{~mm}$ day $^{-1}$ over land and ocean combined. In the eastern Pacific rain maximum the TRMM and GPCP mean values are nearly equal, very different from the other tropical rainy areas where TRMM estimates are higher. This regional difference may indicate that the TRMM merged product is better at taking into account the vertical structure of the rain systems and the difference in structure between the western and eastern (shallower) Pacific convection.

The monthly patterns produced with the TRMM merged data process clearly show the evolution of the ENSO tropical precipitation pattern from early 1998 (El Niño) through early 1999 (La Niña) and beyond. The El Niño minus La Niña difference map shows the eastern Pacific maximum, the maritime continent minima and other tropical and mid-latitude features, very similar to those detected by the GPCP analyses. The integrated tropical ocean differences associated with the ENSO event vary between TRMM, GPCP and other estimates and emphasize the need for additional validation and 


\section{REFERENCES}

Adler, R.F., A.J. Negri, P.R. Keehn, and I.M. Hakkarinen, 1993: Estimation of monthly rainfall over Japan and surrounding waters from a combination of low-orbit microwave and geosynchronous IR data. J. Appl. Meteor., 32, 335-356.

Adler, R. F., G. J. Huffman, and P. R. Keehn, 1994: Global tropical rain estimates from microwave-adjusted geosynchronous IR data. Remote Sensing Reviews, 11, 125-152.

Arkin, P.A., and B.N. Meisner, 1987: The relationship between large-scale convective rainfall and cold cloud over the Western Hemisphere during 1982-1984. Mon. Wea. Rev., 115, 51-74.

Curtis, S., and R. Adler, 1999: ENSO indices based on patterns of satellite derived precipitation. J. Climate, in review.

Curtis, S., R. Adler, G. Huffman, D. Bolvin, and E. Nelkin, 1999: Global precipitation during the 1997-98 El Niño and initiation of the 1998-99 La Niña. J. Geophys. Res.Atmospheres, in review.

Haddad, Z.S., E.A. Smith, C.D. Kummerow, T. Iguchi, M.R. Farrar, S.L. Durden, M. Alves, and W.S. Olson, 1997: The TRMM 'Day-1' radar/radiometer combined rainprofiling algorithm. J. Met. Soc. Japan 75, 799-809.

Huffman, G.J., 1997: Estimates of Root-Mean-Square random error for finite samples of estimated precipitation. J. Appl. Meteor., 36, 1191-1201.

Huffman, G.J., R.F. Adler, P. Arkin, A. Chang, R. Ferraro, A. Gruber, J. Janowiak, A. McNab, B. Rudolf, U. Schneider, 1997: The Global Precipitation Climatology Project (GPCP) Version 1 Data Set. Bull. Amer. Meteor. Soc., 78, 5-20.

Kummerow, C., W.S. Olson, and L. Giglio, 1996: A simplified scheme for obtaining precipitation and vertical hydrometer profiles from passive microwave sensors. IEEE Trans. Geosci. Remote Sens., 34, 1213-1232.

Kummerow, C.D., J. Simpson, O. Thiele, W. Barnes, A.T.C. Chang, E. Stocker, R. F. Adler, A. Hou, R. Kakar, F. Wentz, P. Ashcroft, T. Kozu, Y. Hong, T. Iguchi, E. Im, Z. Haddad, G.J. Huffman, T. Krishnamurti, B. Ferrier, W.S. Olson, E. Zipser, and E.A. Smith, 1999: The status of the Tropical Rainfall Measuring Mission (TRMM) after 2 years in orbit. J. Appl. Meteor., submitted.

Morrissey, M.L., M.A. Shafer, S.E. Postawko, and B. Gibson, 1995: The Pacific rain gage rainfall database. Water Resources Research, 31, 2111-2113.

Rosenfeld, D., E. Amitai, and D.B. Wolff, 1995: Classification of rain regimes by the 3dimensional properties of reflectivity fields. J. Appl. Meteor., 34, 198-211. 


\section{Table Captions}

Table 1. Averages of oceanic, land, and total tropical $\left(37^{\circ} \mathrm{N}-\mathrm{S}\right)$ rainfall for $1998 \mathrm{in} \mathrm{mm}$ day $^{-1}$ for the TRMM and GPCP Merged Analyses.

Table 2. Averages of rainfall for $1998 \mathrm{in} \mathrm{mm} \mathrm{day}^{-1}$ for seven sample regions (shown in Fig. 5) for TRMM and GPCP Merged Analyses. The TRMM/GPCP ratio is also given. 
TRMM Merged Analysis, TMI processed with GPROF, and TRMM Combined Instrument (TCI). Note that the last three start in January 1998 with the first full calendar month of TRMM.

Figure 12. Time histories of monthly precipitation averaged over a) Central/Eastern Pacific Ocean (PAC, Fig. 5) and b) Indian Ocean (IND, Fig. 5) in mm day ${ }^{-1}$ for GPCP Merged Analysis, SSM/I processed with GPROF, and TRMM Merged Analysis.

Figure 13. Scattergrams of monthly tropical Pacific atoll raingauge data versus a) TRMM Merged Analysis precipitation and b) GPCP Merged Analysis precipitation for January 1998-May 1999 in $\mathrm{mm} \mathrm{month}^{-1}$. All data are analyzed on a $2.5^{\circ} \times 2.5^{\circ}$ latitude/longitude grid. The 1-to-1 line is heavy solid and the least-squares regression line is light solid.

Figure 14. Scattergram of pentad (5-day) TRMM Ground Validation precipitation from Kwajalein versus TRMM AGPI for January, February, April, August, and September 1998 in $\mathrm{mm} \mathrm{pentad}^{-1}$. All data are analyzed on a $1^{\circ} \times 1^{\circ}$ latitude/longitude grid. The 1-to-1 line is heavy solid.

Figure 15. Scattergrams of scaled monthly TRMM Ground Validation precipitation from Kwajalein versus a) scaled monthly TRMM AGPI precipitation and b) monthly GPCP Merged Analysis precipitation for $1998 \mathrm{in} \mathrm{mm} \mathrm{month} h^{-1}$. All data are analyzed on a $1^{\circ} \times 1^{\circ}$ latitude/longitude grid. The 1-to-1 line is heavy solid.

Figure 16. Scattergrams of pentad (5-day) TRMM Ground Validation precipitation from a) Houston, TX, and b) Melbourne, FL, versus TRMM AGPI precipitation for 1998 in $\mathrm{mm}$ pentad ${ }^{-1}$. All data are analyzed on a $1^{\circ} \times 1^{\circ}$ latitude/longitude grid. The 1 -to-1 line is heavy solid.

Figure 17. Scattergrams of monthly Global Precipitation Climatology Project raingauge data versus a) TRMM AGPI precipitation and b) TRMM Merged Analysis precipitation for 1998 in mm month ${ }^{-1}$. Only grid boxes with at least 2 rain gauges are included in the plot. All data are analyzed on a $1^{\circ} \times 1^{\circ}$ latitude/longitude grid. The 1-to-1 line is heavy solid and the least-squares regression line is light solid.

Figure 18. Scattergrams of scaled monthly TRMM Ground Validation precipitation from a) Houston, TX, and b) Melbourne, FL, versus monthly TRMM Merged Analysis precipitation for 1998 in $\mathrm{mm}$ month ${ }^{-1}$. All data are analyzed on a $1^{\circ} \times 1^{\circ}$ latitude/longitude grid. The 1-to-1 line is heavy solid. 
Table 1. Averages of oceanic, land, and total tropical $\left(37^{\circ} \mathrm{N}-\mathrm{S}\right)$ rainfall for $1998 \mathrm{in} \mathrm{mm}$ day $^{-1}$ for the TRMM and GPCP Merged Analyses.

\begin{tabular}{|c|c|c|c|}
\cline { 2 - 4 } \multicolumn{1}{c|}{} & $\begin{array}{c}\text { Ocean } \\
\left(\mathbf{m m ~ d a y ~}^{-1}\right)\end{array}$ & $\begin{array}{c}\text { Land } \\
\left(\mathbf{m m ~ d a y ~}^{-1}\right)\end{array}$ & $\begin{array}{c}\text { Total } \\
\left(\mathbf{m m ~ d a y}^{-1}\right)\end{array}$ \\
\hline TRMM Merged Analysis & 3.3 & 2.6 & 3.1 \\
\hline $\begin{array}{c}\text { Global Precipitation Climatology Project } \\
\text { (GPCP) Merged Analysis }\end{array}$ & 3.0 & 2.5 & 2.9 \\
\hline
\end{tabular}


Table 2. Averages of rainfall for 1998 in $\mathrm{mm}^{-1 a y^{-1}}$ for seven sample regions (shown in Fig. 5) for TRMM and GPCP Merged Analyses. The TRMM/GPCP ratio is also given.

\begin{tabular}{|c|c|c|c|c|c|}
\hline & $\begin{array}{l}\text { Box } \\
\text { Num. }\end{array}$ & $\begin{array}{c}\text { Box Size } \\
\left.\text { ('lat } x^{\circ} \text { lon }\right)\end{array}$ & $\begin{array}{c}\text { TRMM } \\
\left(\mathrm{mm} \mathrm{day}^{-1}\right)\end{array}$ & $\begin{array}{c}\text { GPCP } \\
\left(\mathrm{mm} \mathrm{day}^{-1}\right)\end{array}$ & $\begin{array}{c}\text { TRMM/GPCP } \\
\text { Ratio } \\
\end{array}$ \\
\hline Eastern Indian Oc. ITCZ & 1 & $10 \times 10$ & 10.6 & 9.1 & 1.16 \\
\hline Western Pacific Oc. ITCZ & 2 & $5 \times 15$ & 6.2 & 5.0 & 1.24 \\
\hline $\begin{array}{c}\text { Western Pacific Oc. } \\
\text { SPCZ }\end{array}$ & 3 & $5 \times 15$ & 11.7 & 8.5 & 1.38 \\
\hline Eastern Pacific Oc. ITCZ & 4 & $5 \times 15$ & 7.6 & 7.3 & 1.04 \\
\hline $\begin{array}{c}\text { Eastern Atlantic Oc. } \\
\text { ITCZ }\end{array}$ & 5 & $5 \times 15$ & 8.4 & 7.3 & 1.15 \\
\hline Northern Pacific Ocean & 6 & $5 \times 20$ & 6.1 & 5.9 & 1.03 \\
\hline Southern Atlantic Ocean & 7 & $10 \times 10$ & 4.9 & 4.4 & 1.11 \\
\hline
\end{tabular}




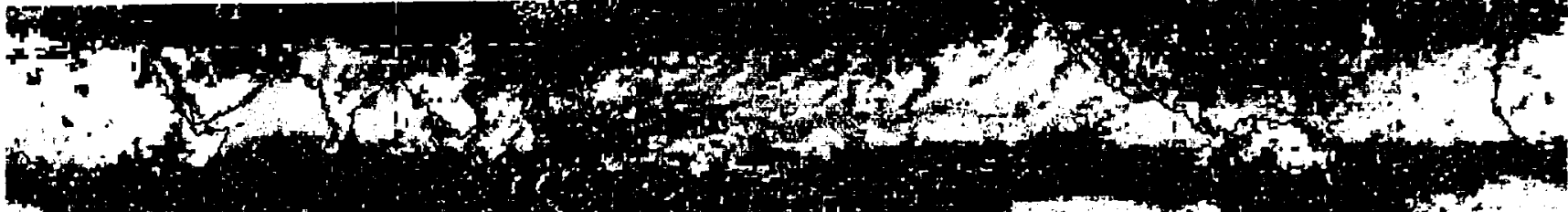

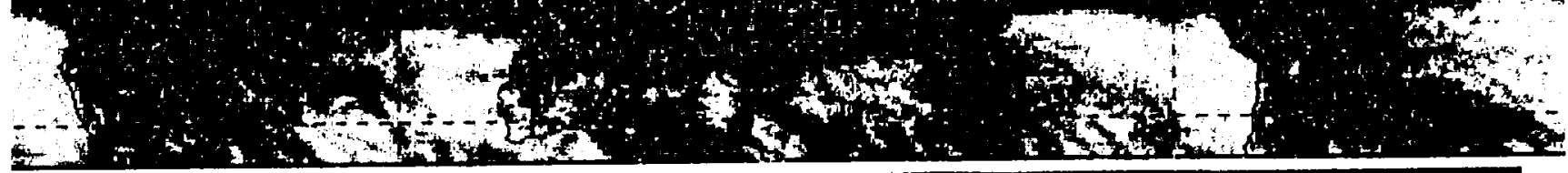
Fine-Grid TCI Precip Jan 1998 $(\mathrm{mm} / \mathrm{d})$

0

48

12

16

$20+$

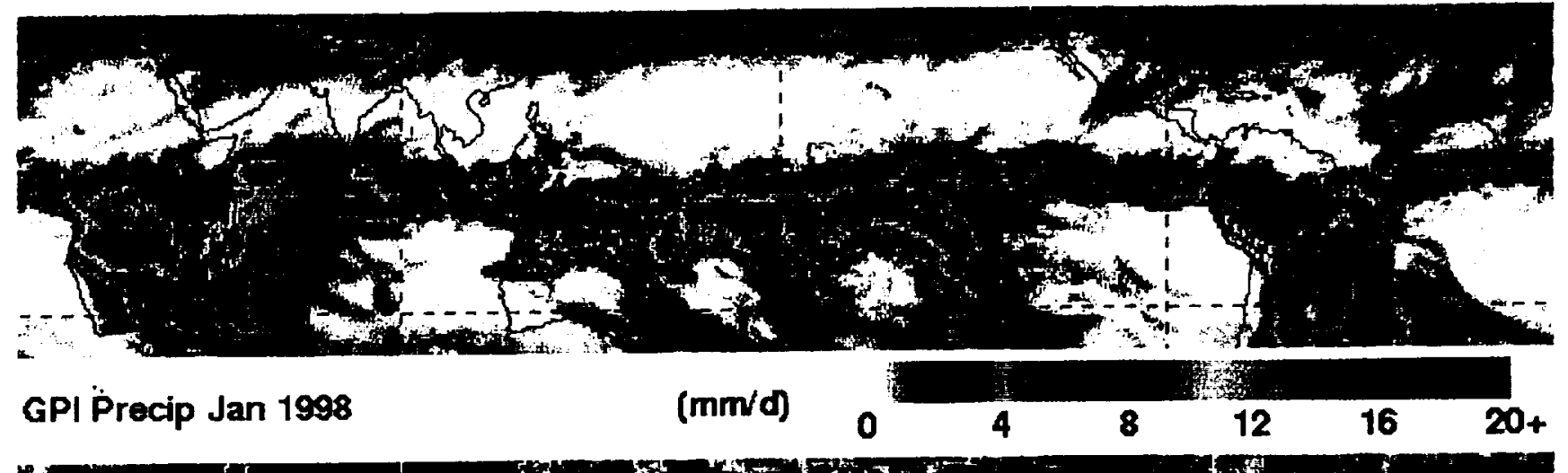

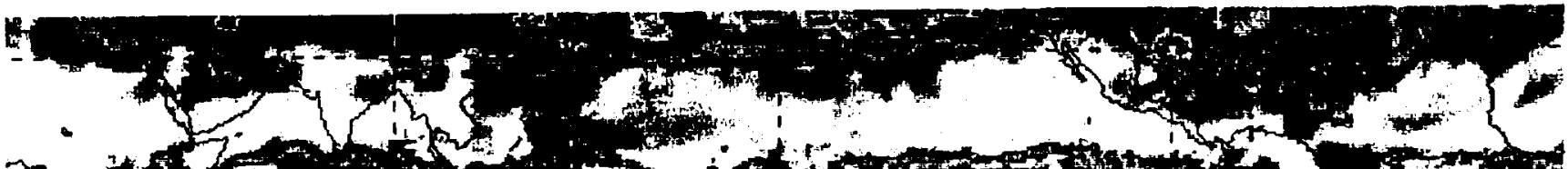
1.

Adjusted GPI (AGPI) Precip Jan 1998 (mm/d)

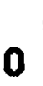

0
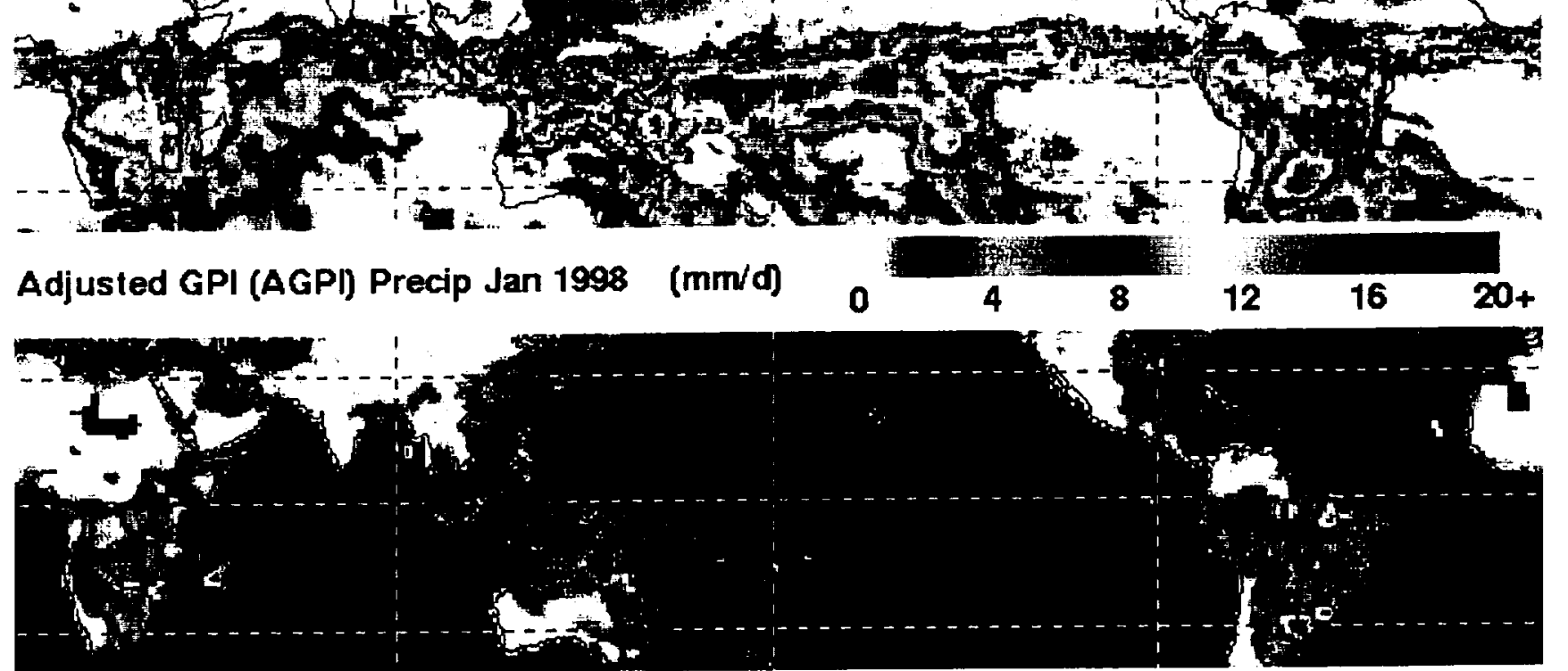

GPCP Gauge Precip Jan 1998

$(\mathrm{mm} / \mathrm{d})$

0

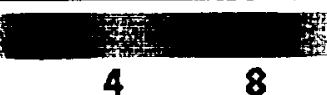

$12 \quad 16 \quad 20+$

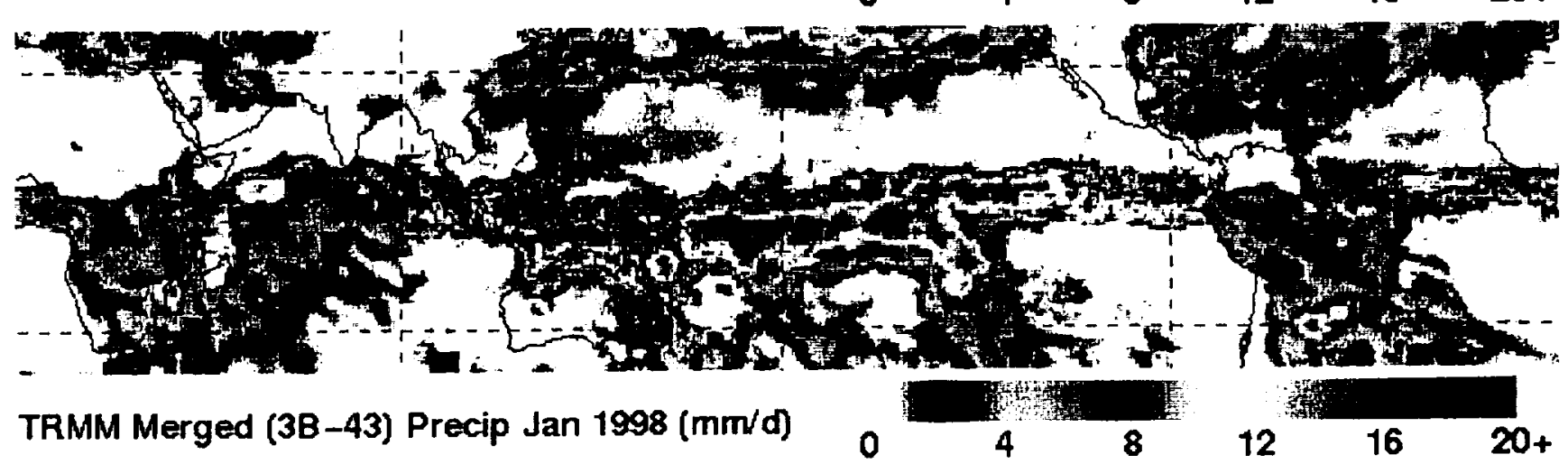

Figure 1 


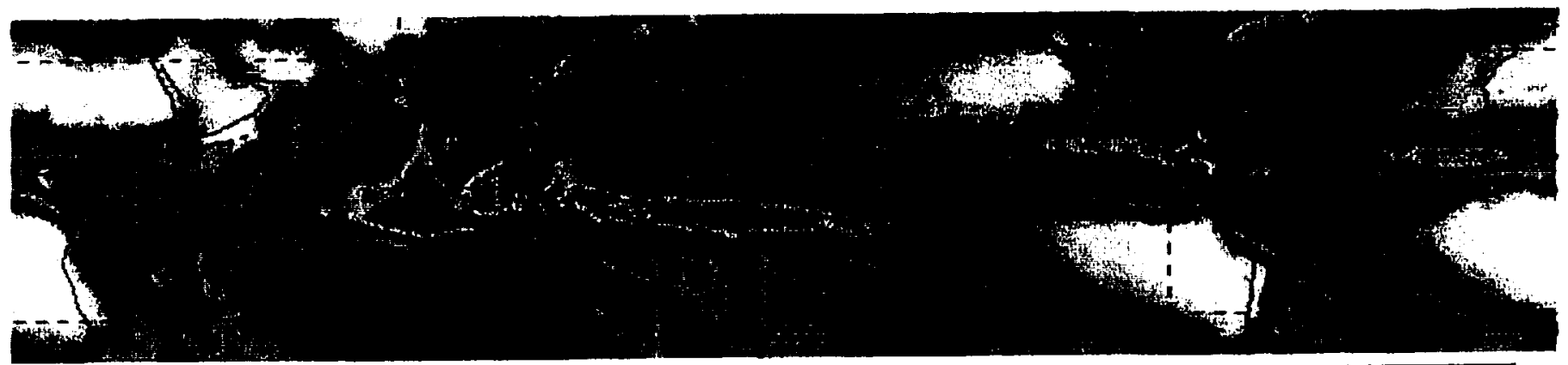

\section{TRMM Merged Annual Precip 1998}

$(\mathrm{mm} / \mathrm{d})$

$\mathbf{0}^{1}$

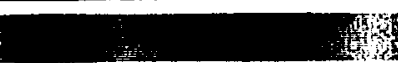

03

6

9

$1215+$

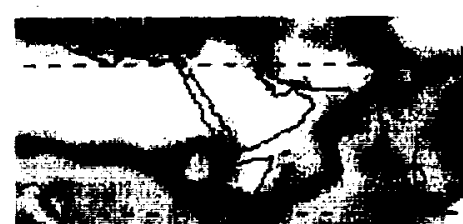

W13
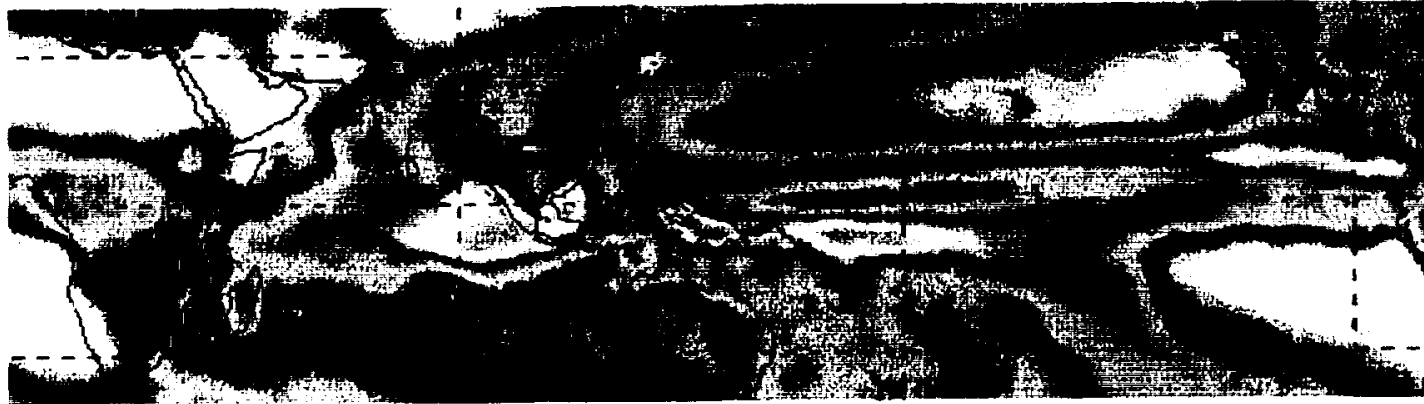

$\begin{array}{ll}9 & 12\end{array}$
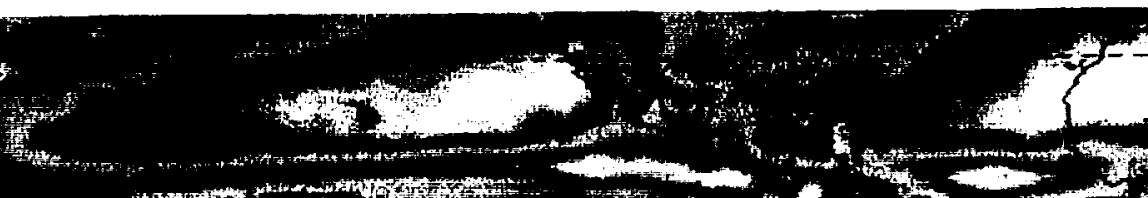
198.
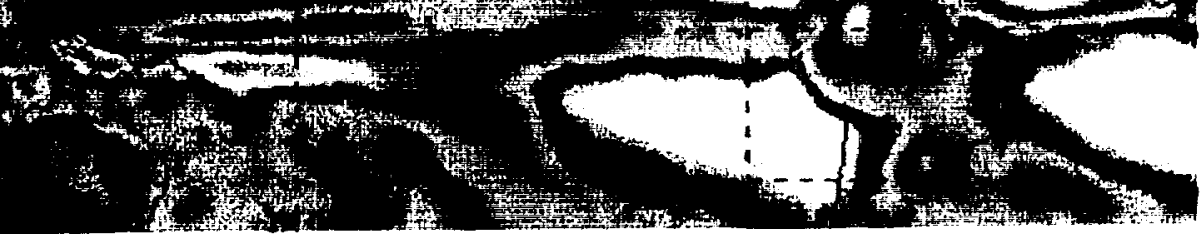

GPCP Merged Annual Precip 1998

$(\mathrm{mm} / \mathrm{d})$

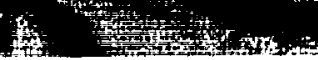
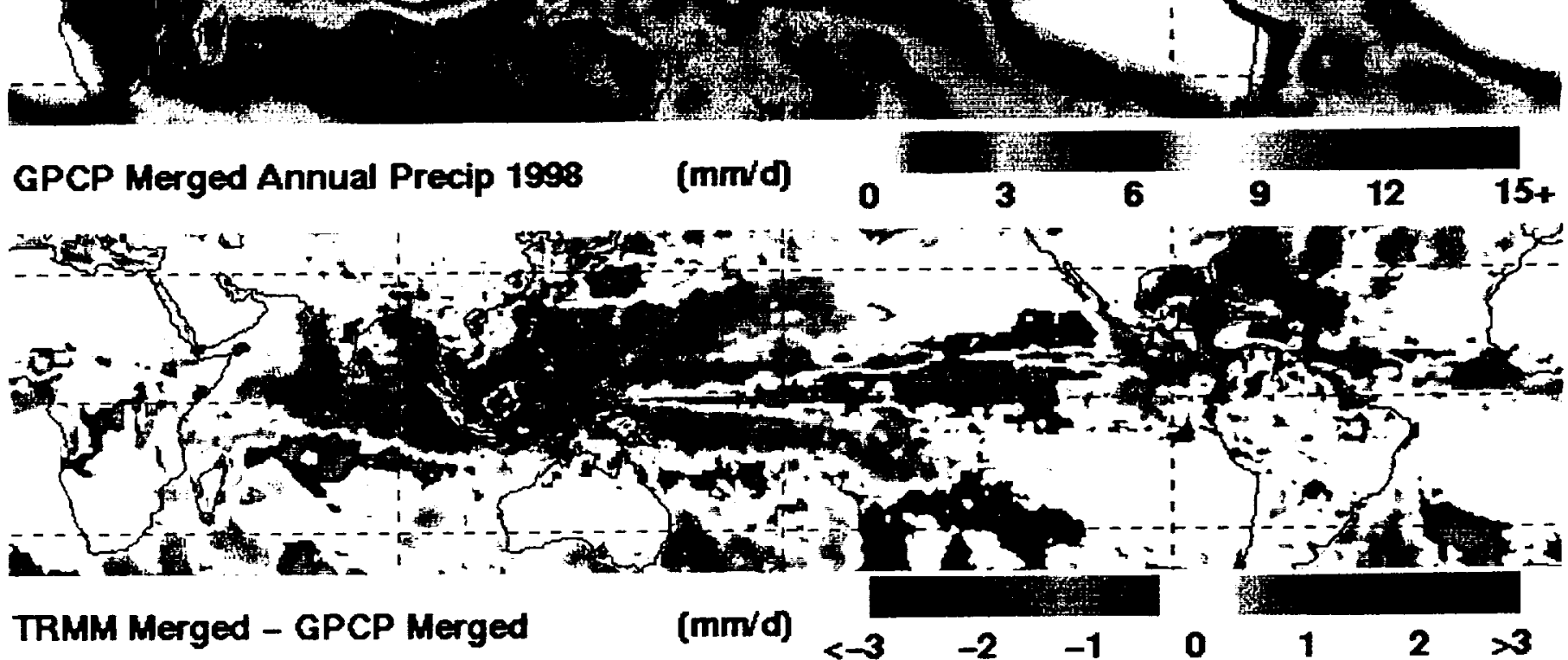


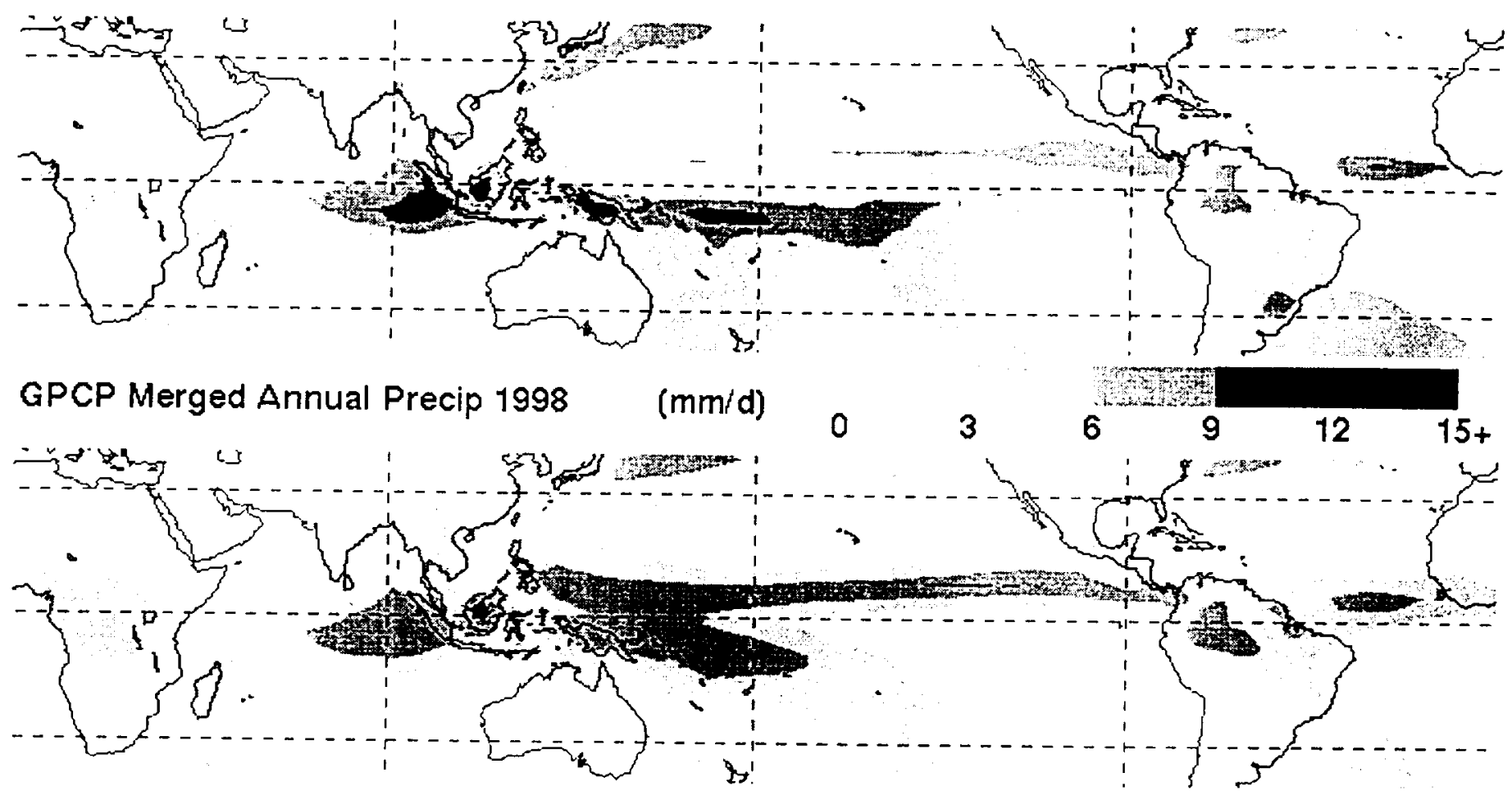

GPCP Climatology Precip 1979-1998 (mm/d) 


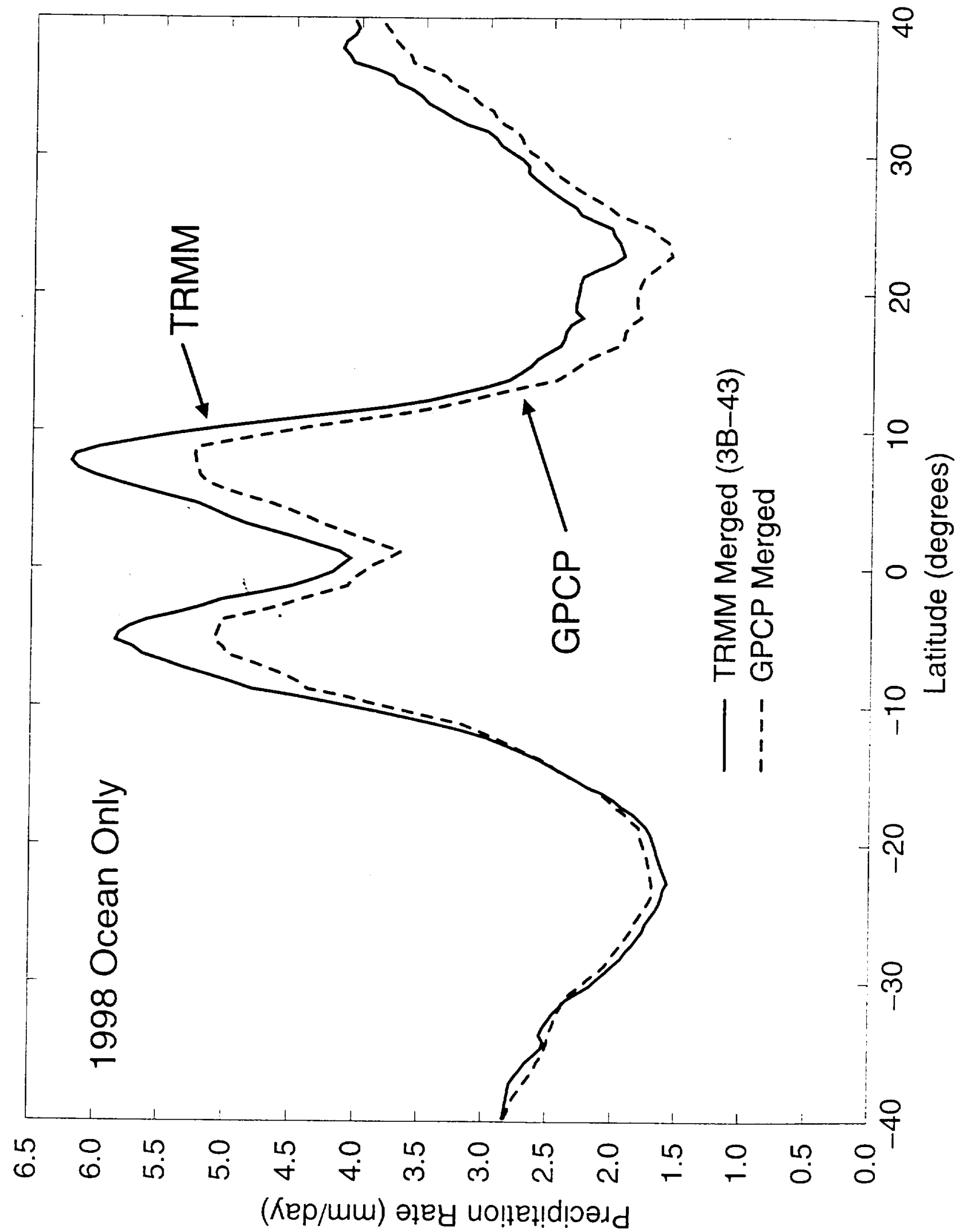

Figure 4 


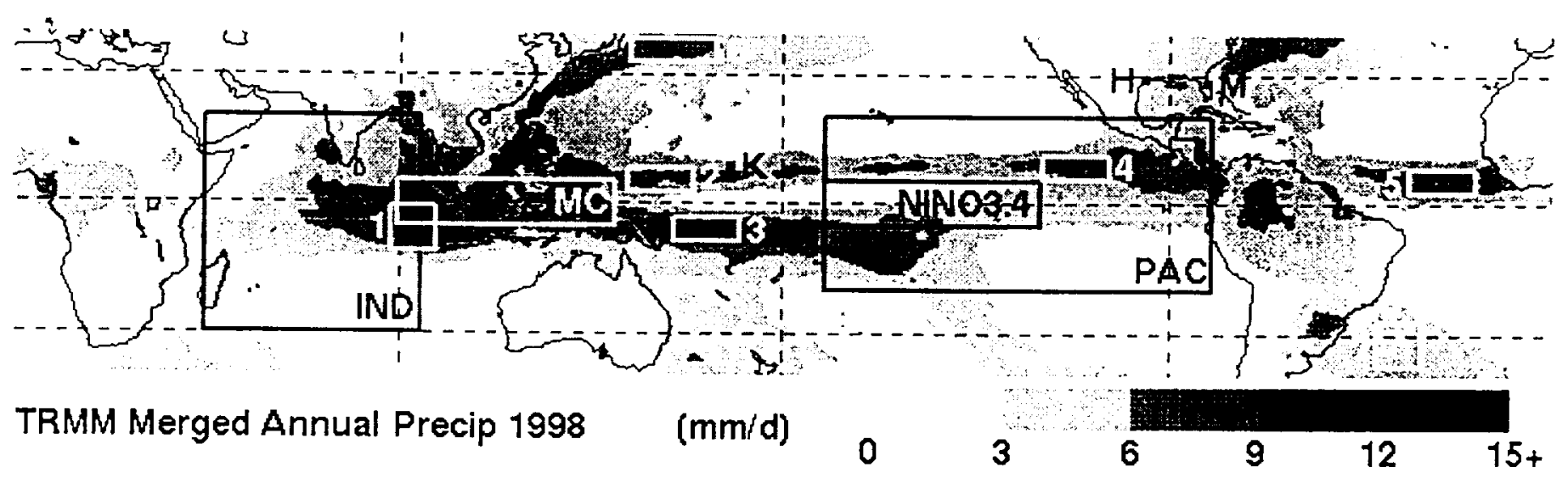

Figure 5 


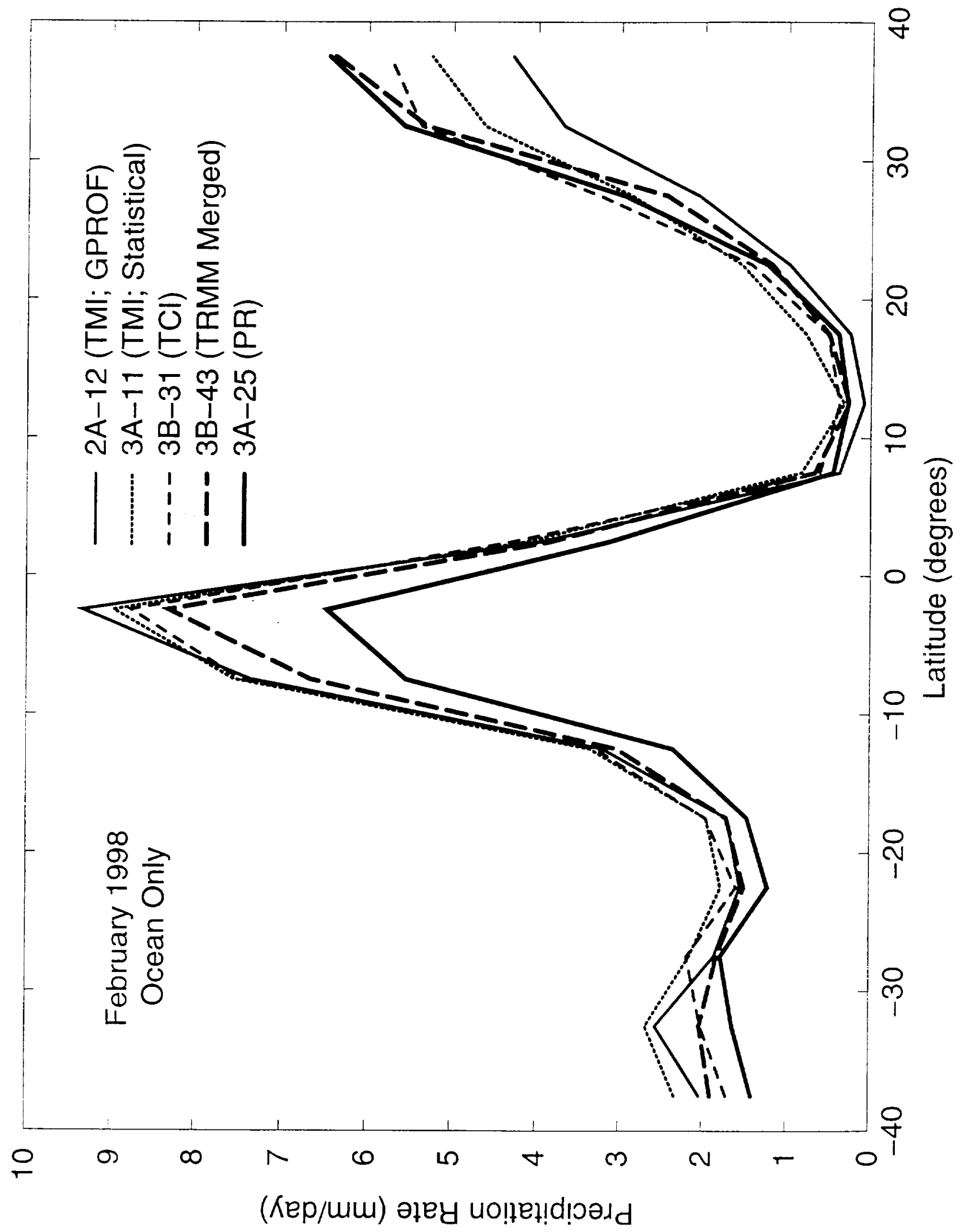

Figure 6 


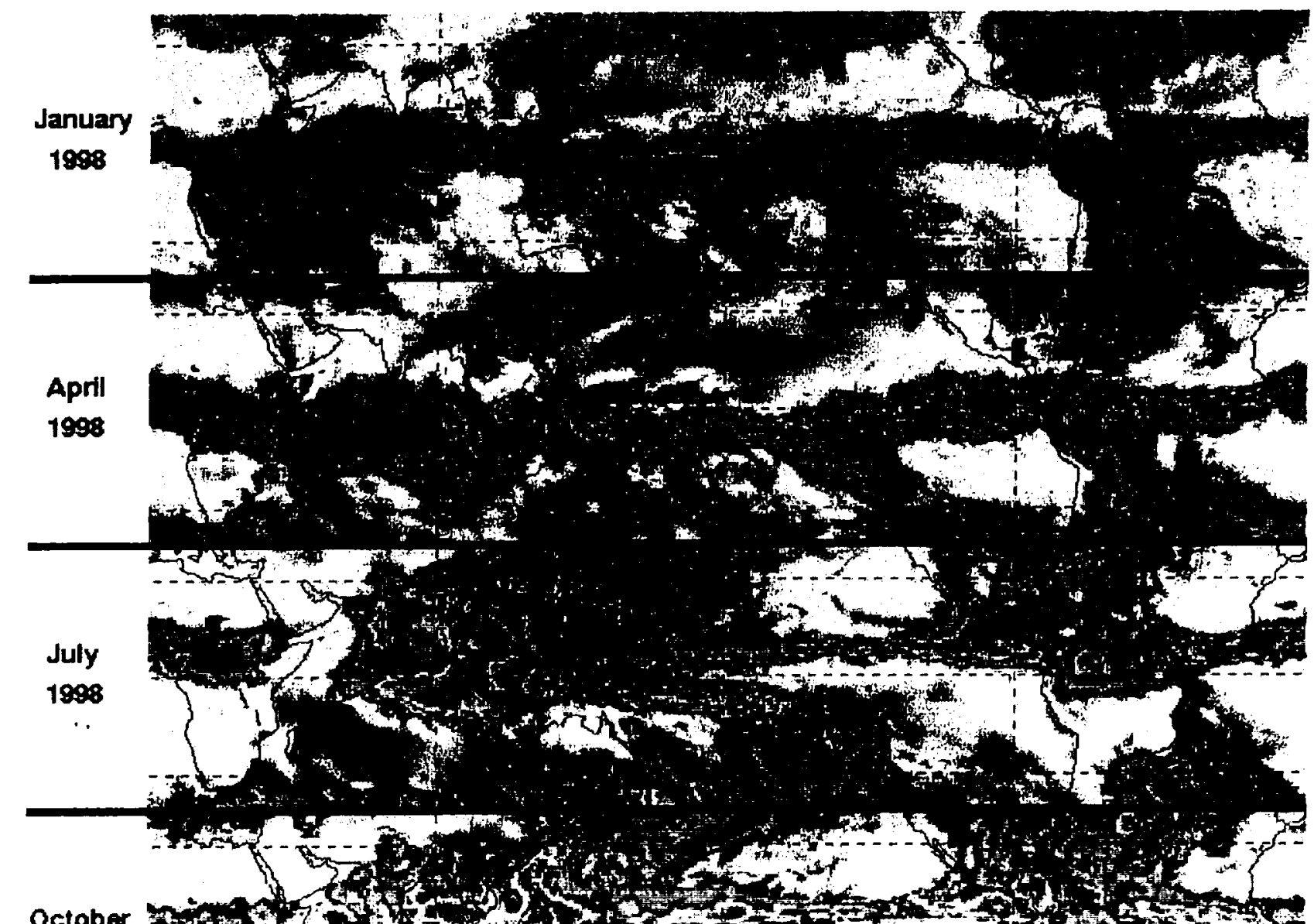

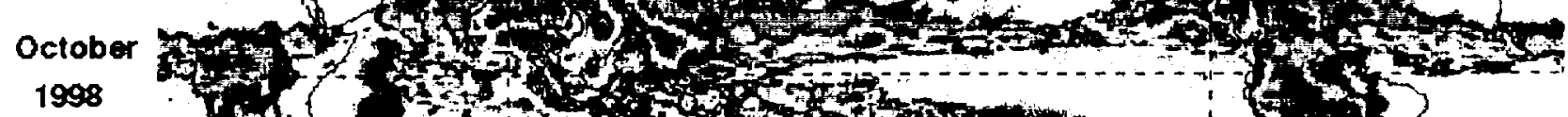

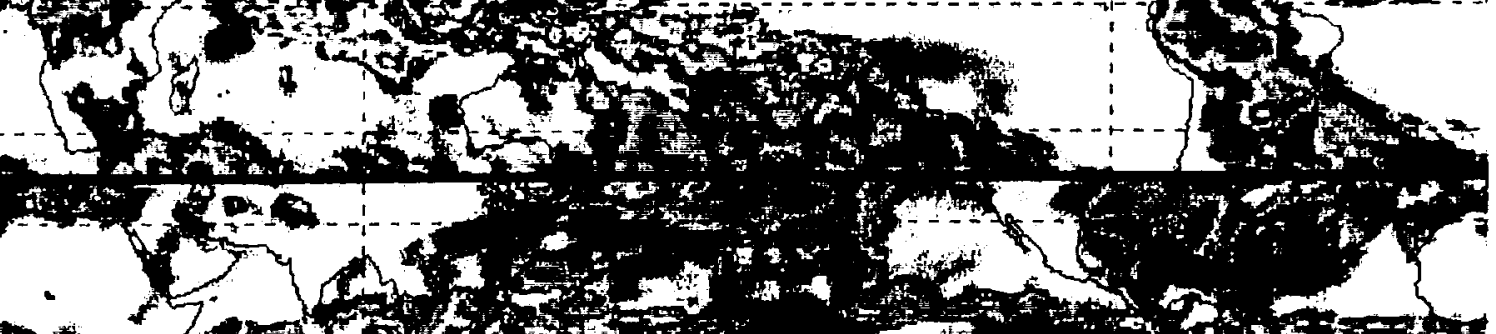

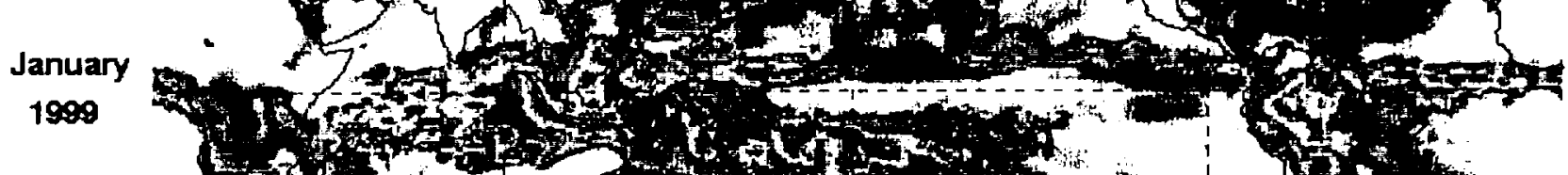

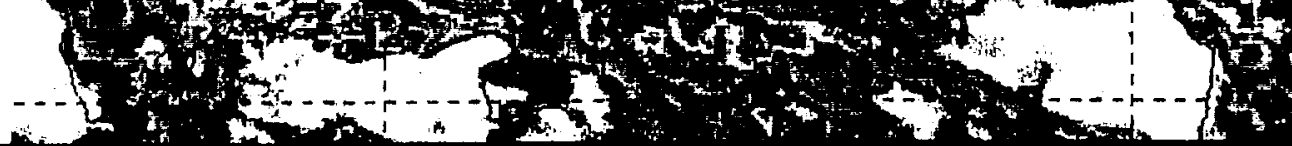

-

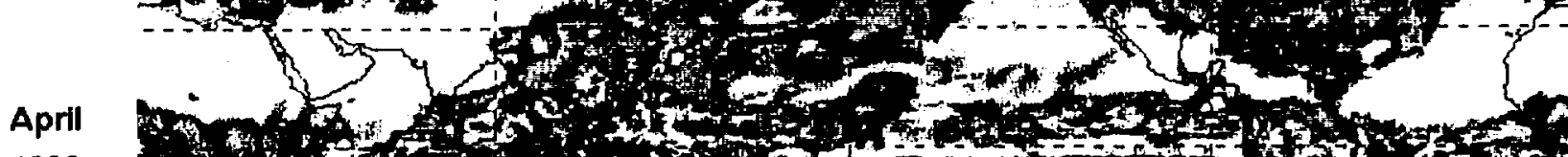
April 1999 ot

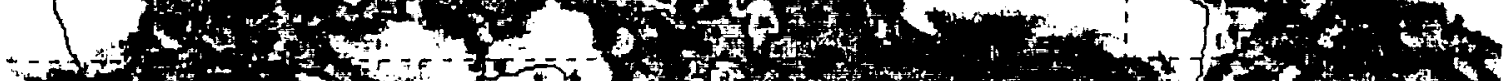
2-

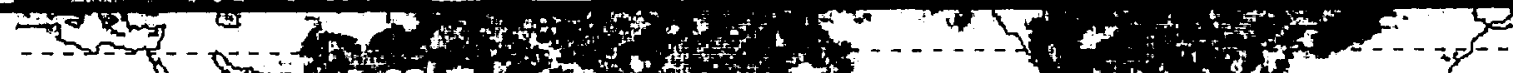

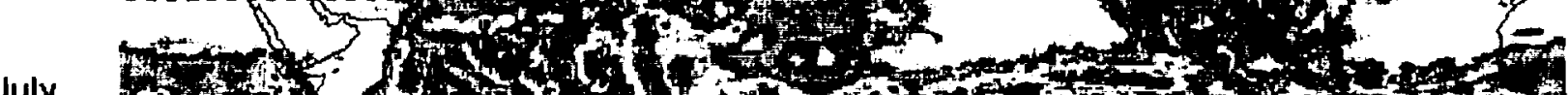

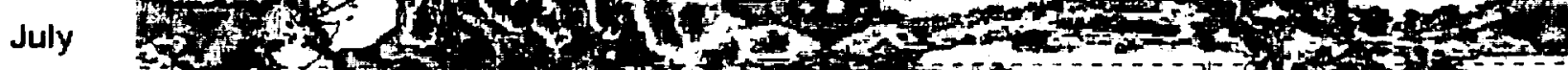
1999

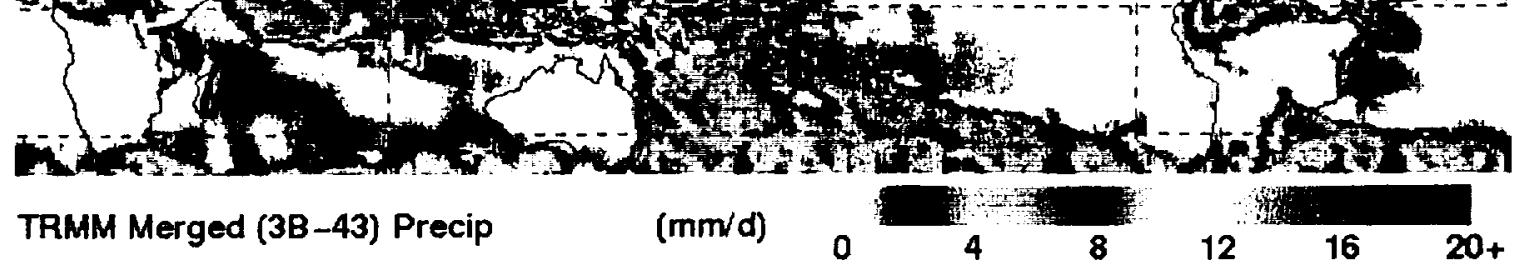




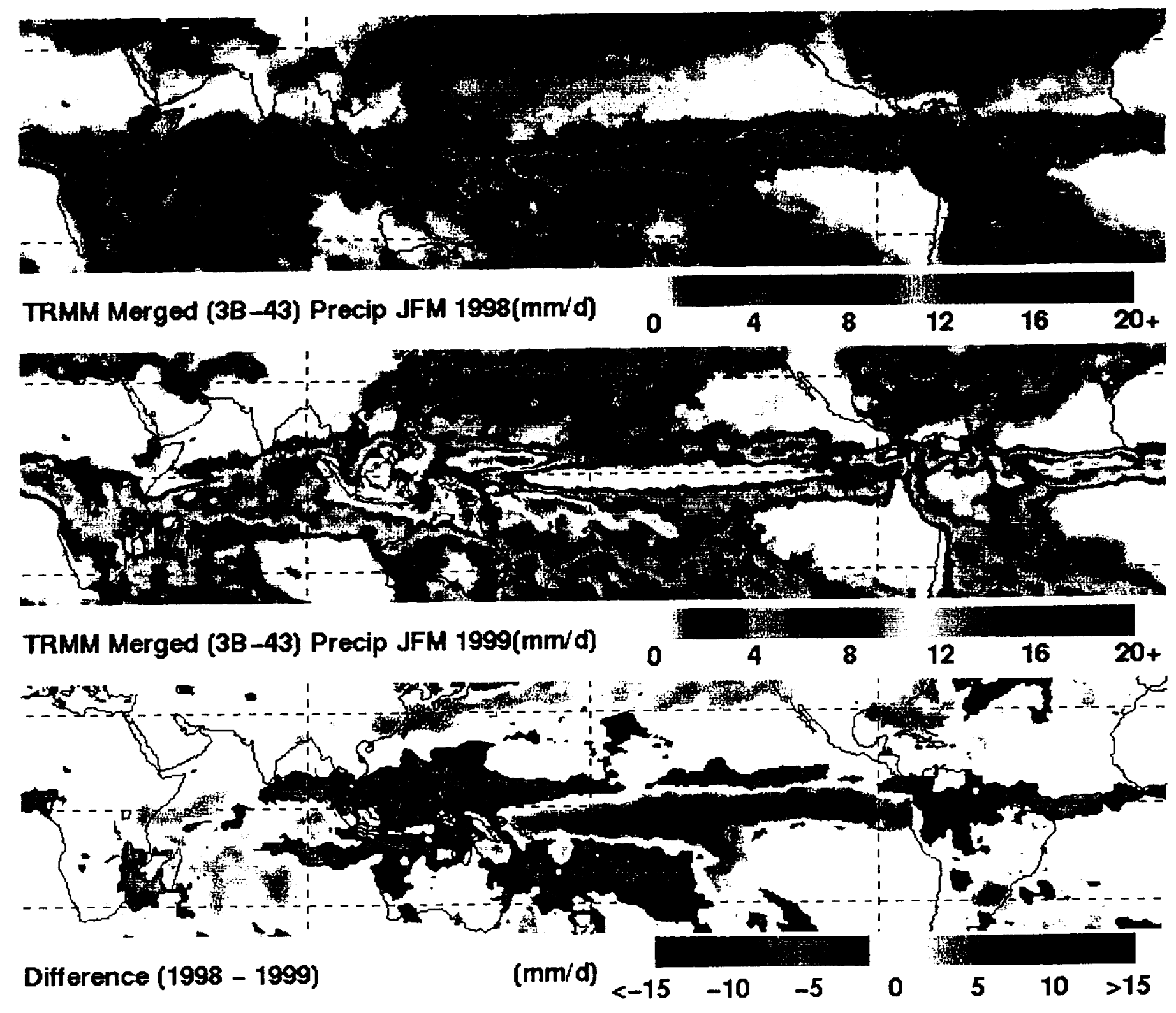

Figure 8 


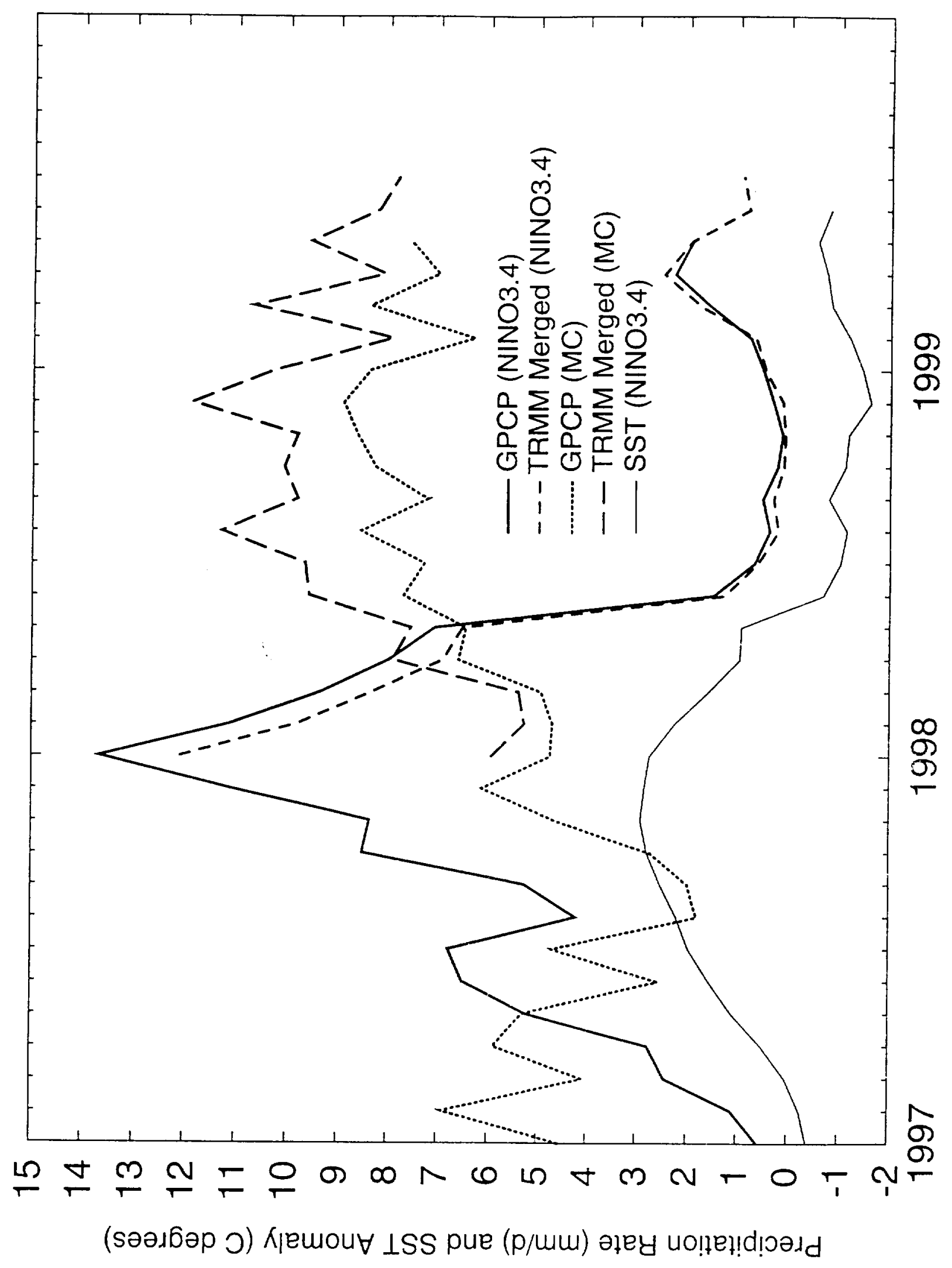

Figure 9 


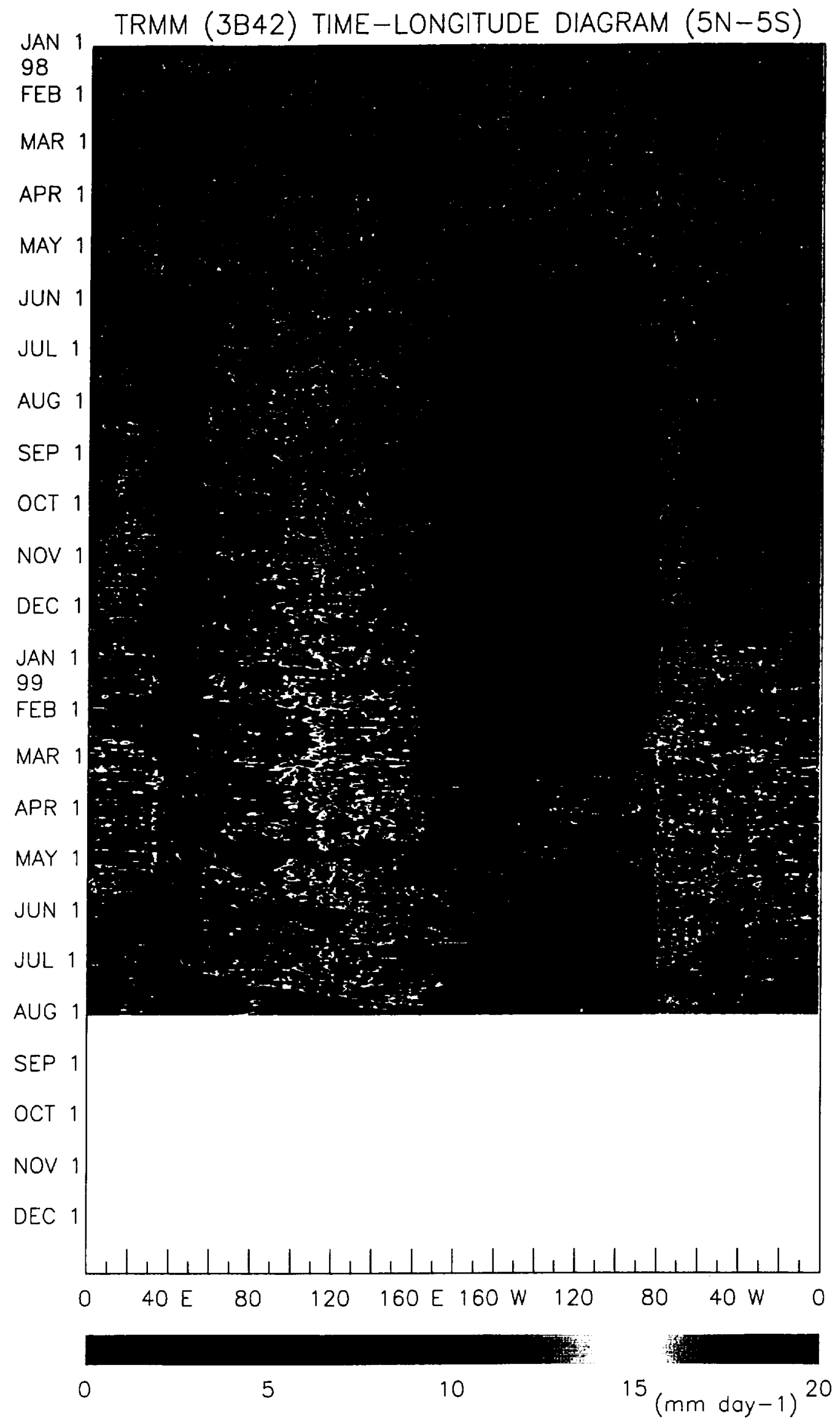

Figure 10 


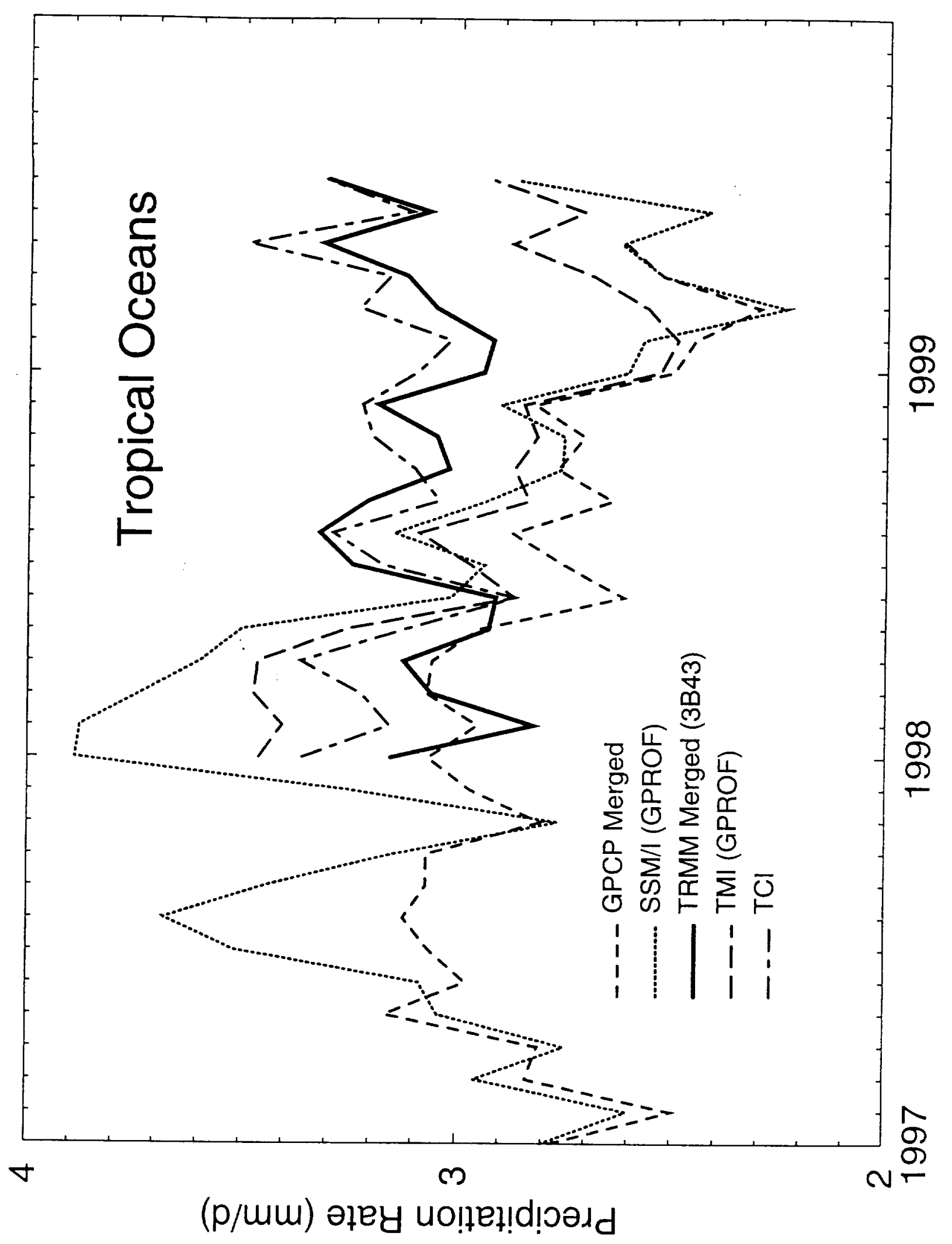

Figure 11 

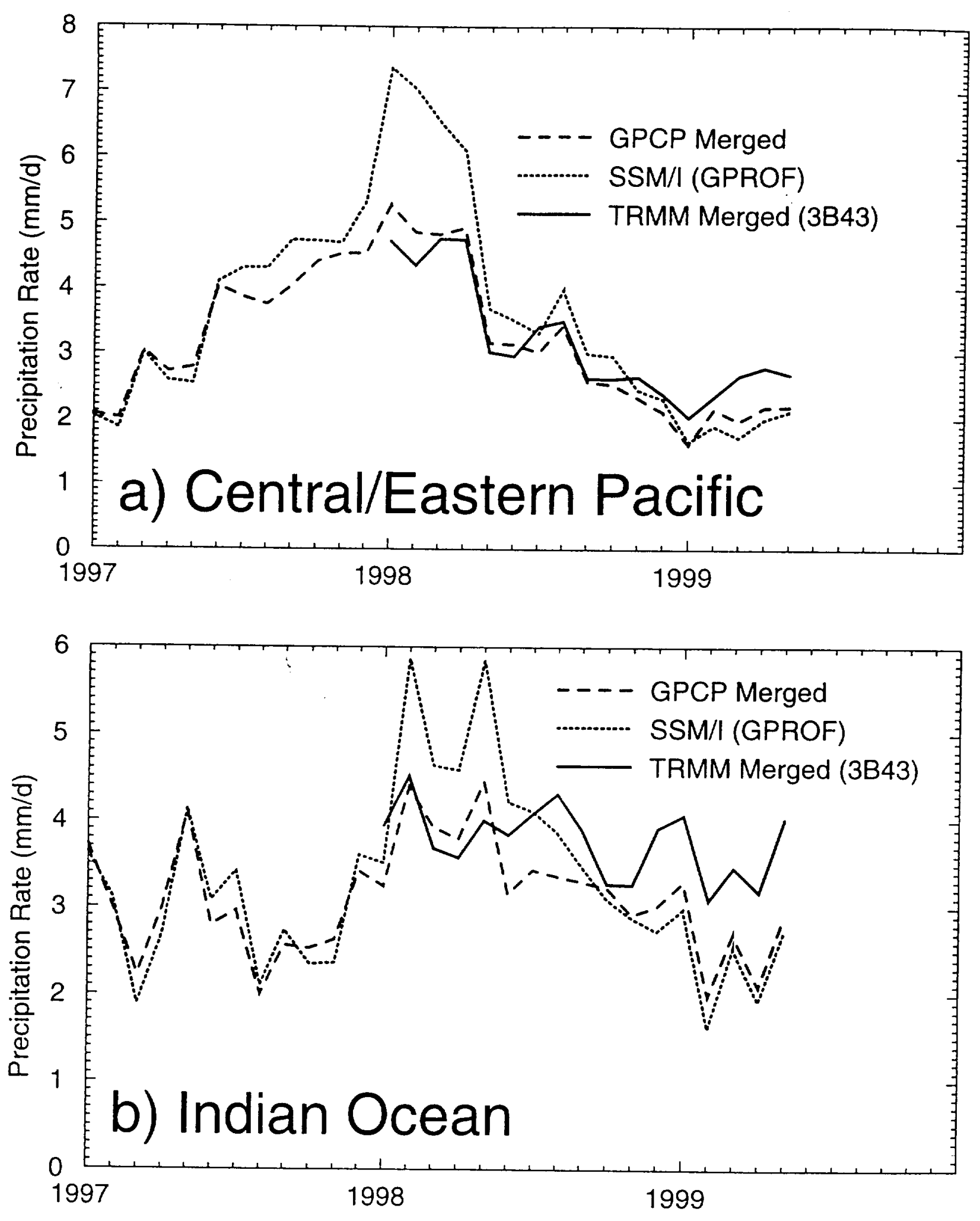

Figure 12 


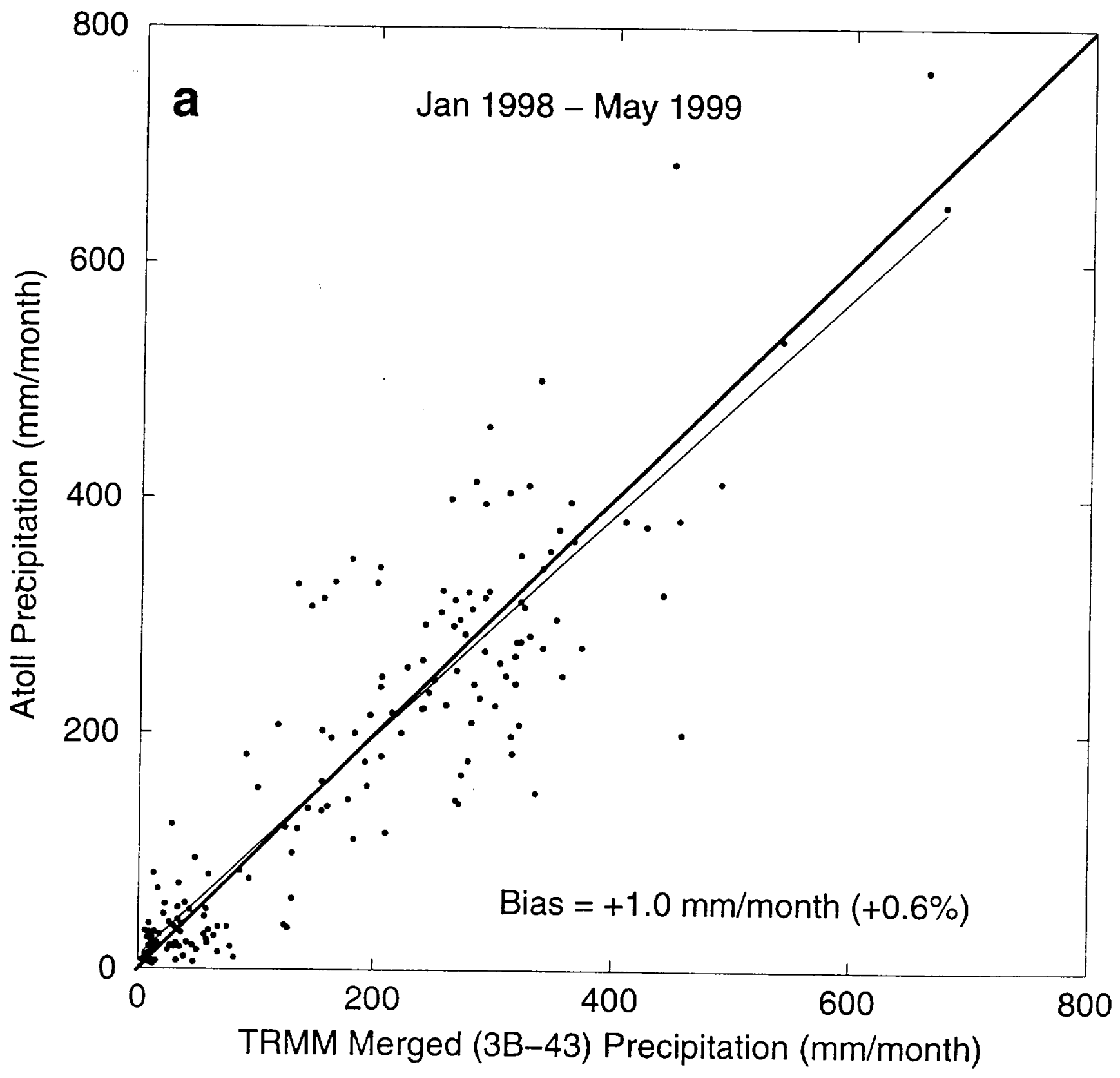

Figure 13a 


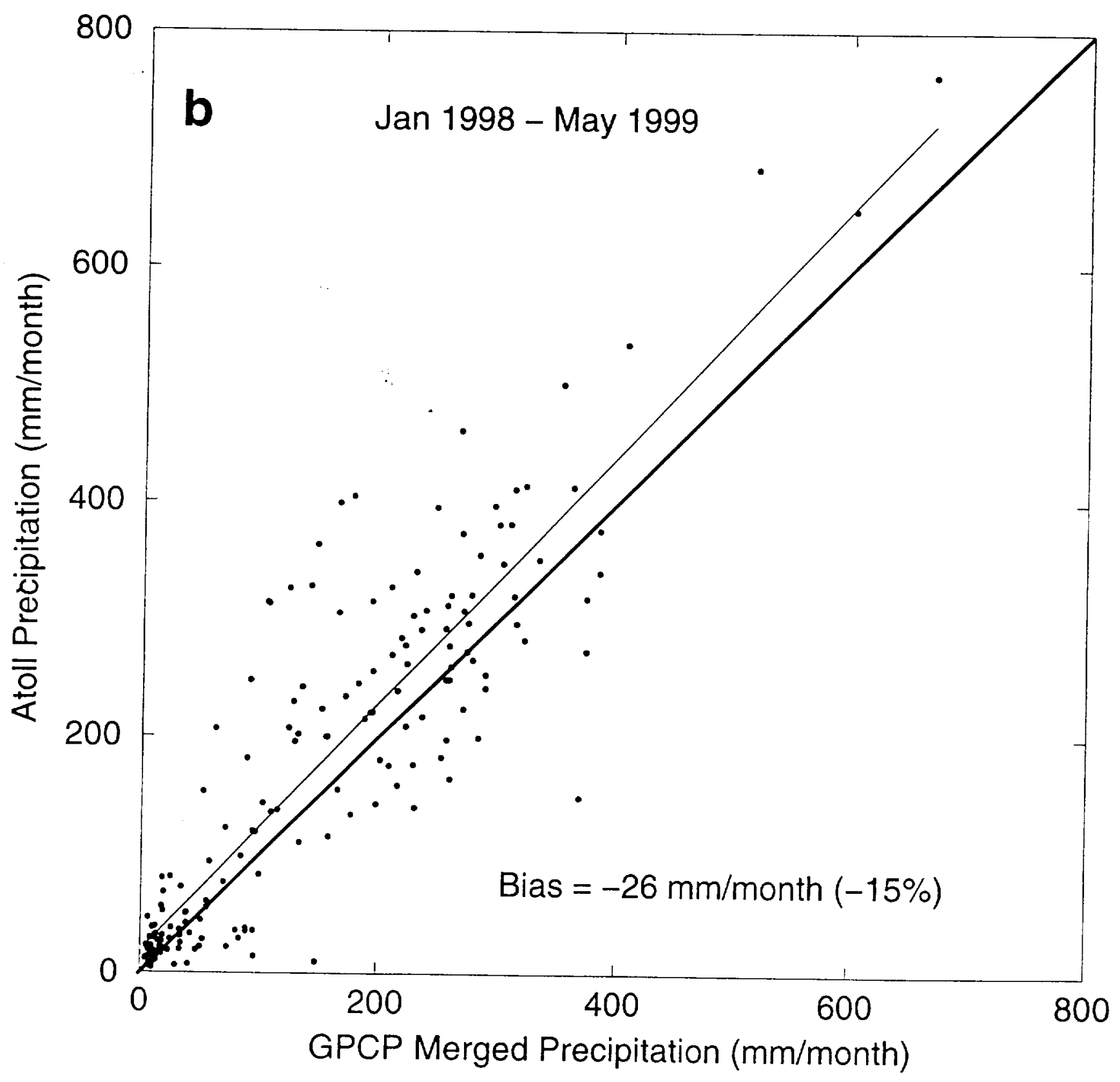

Figure 13b 


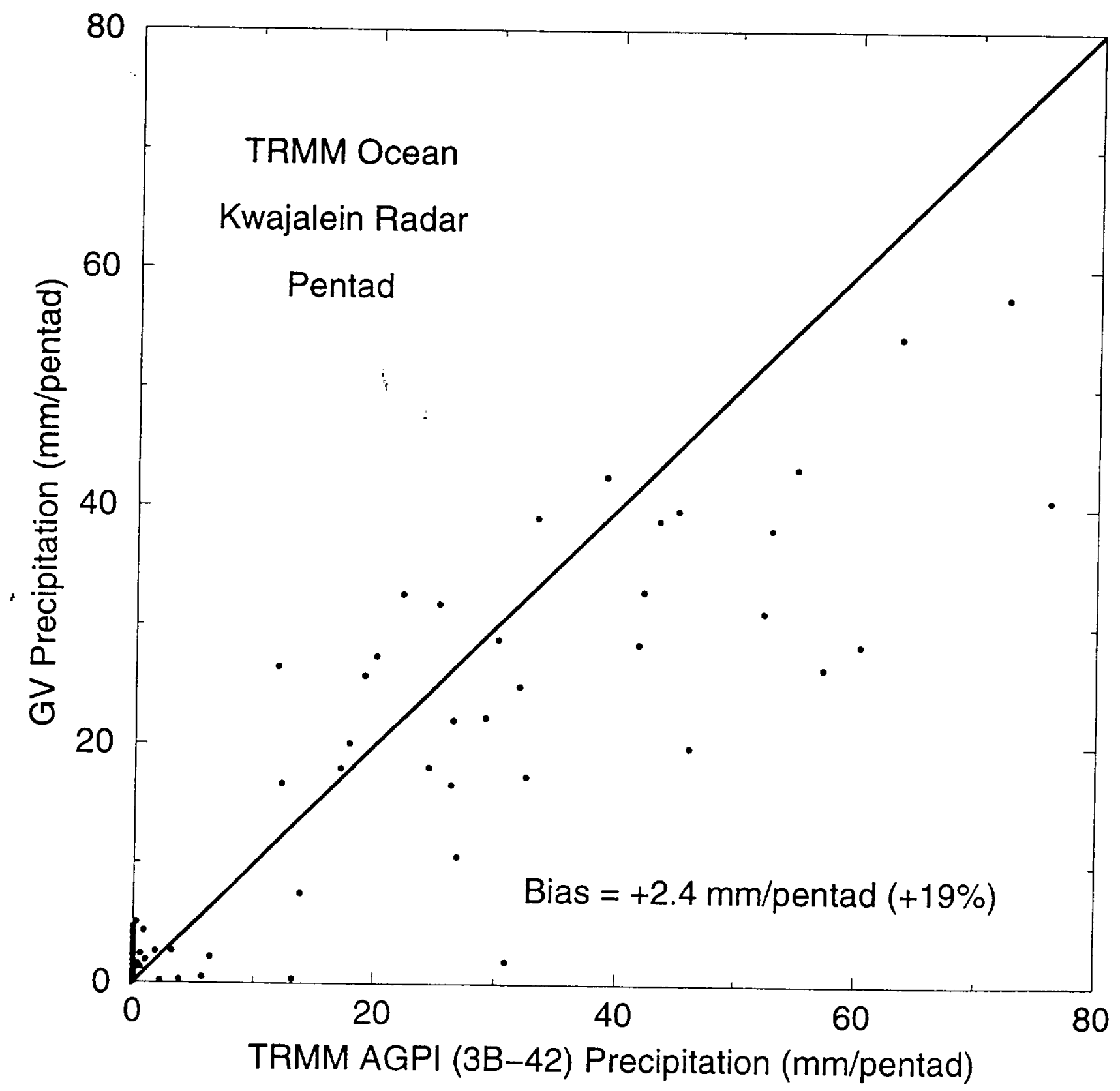

Figure 14 


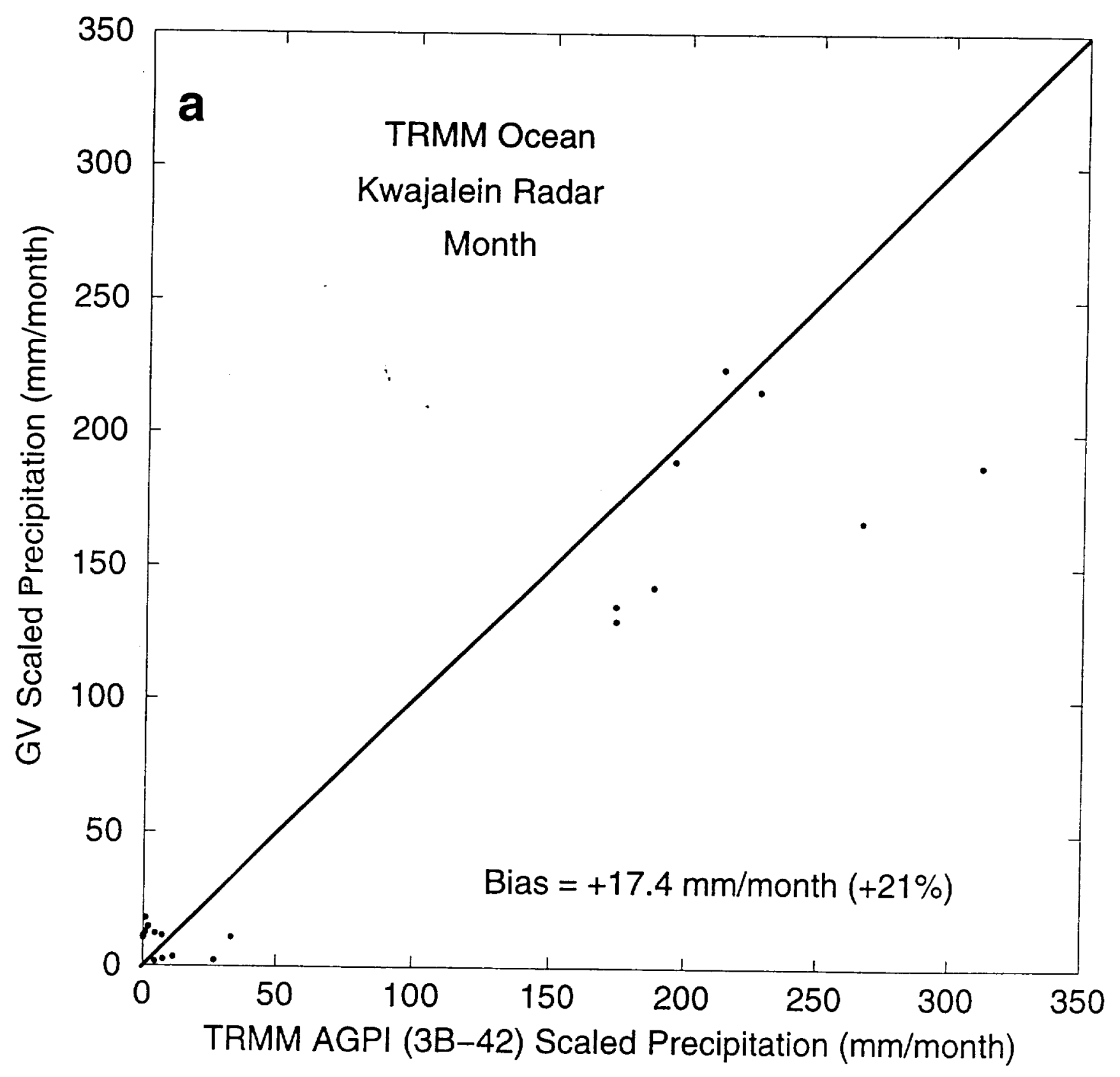

Figure 15a 


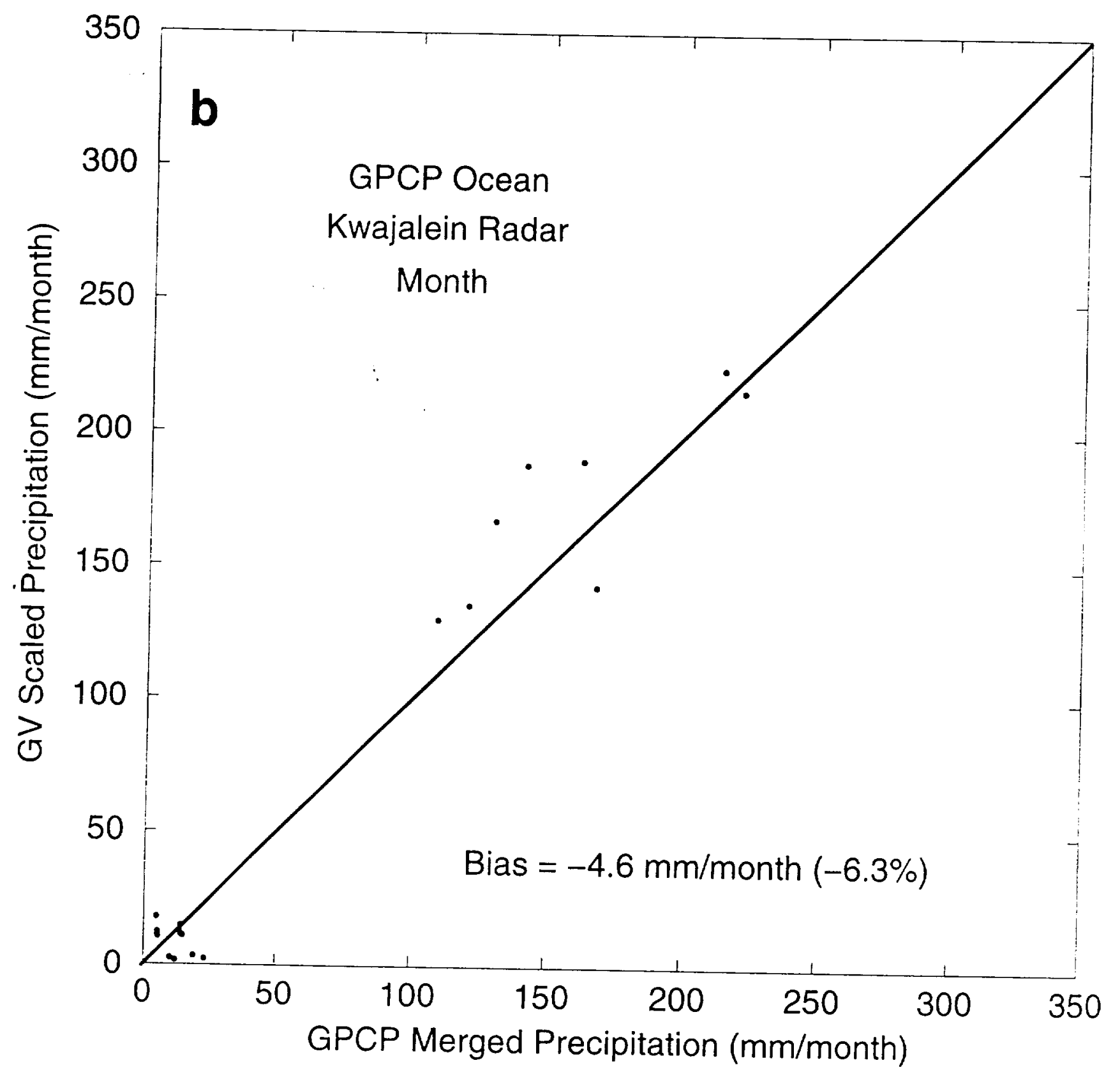

Figure 15b 


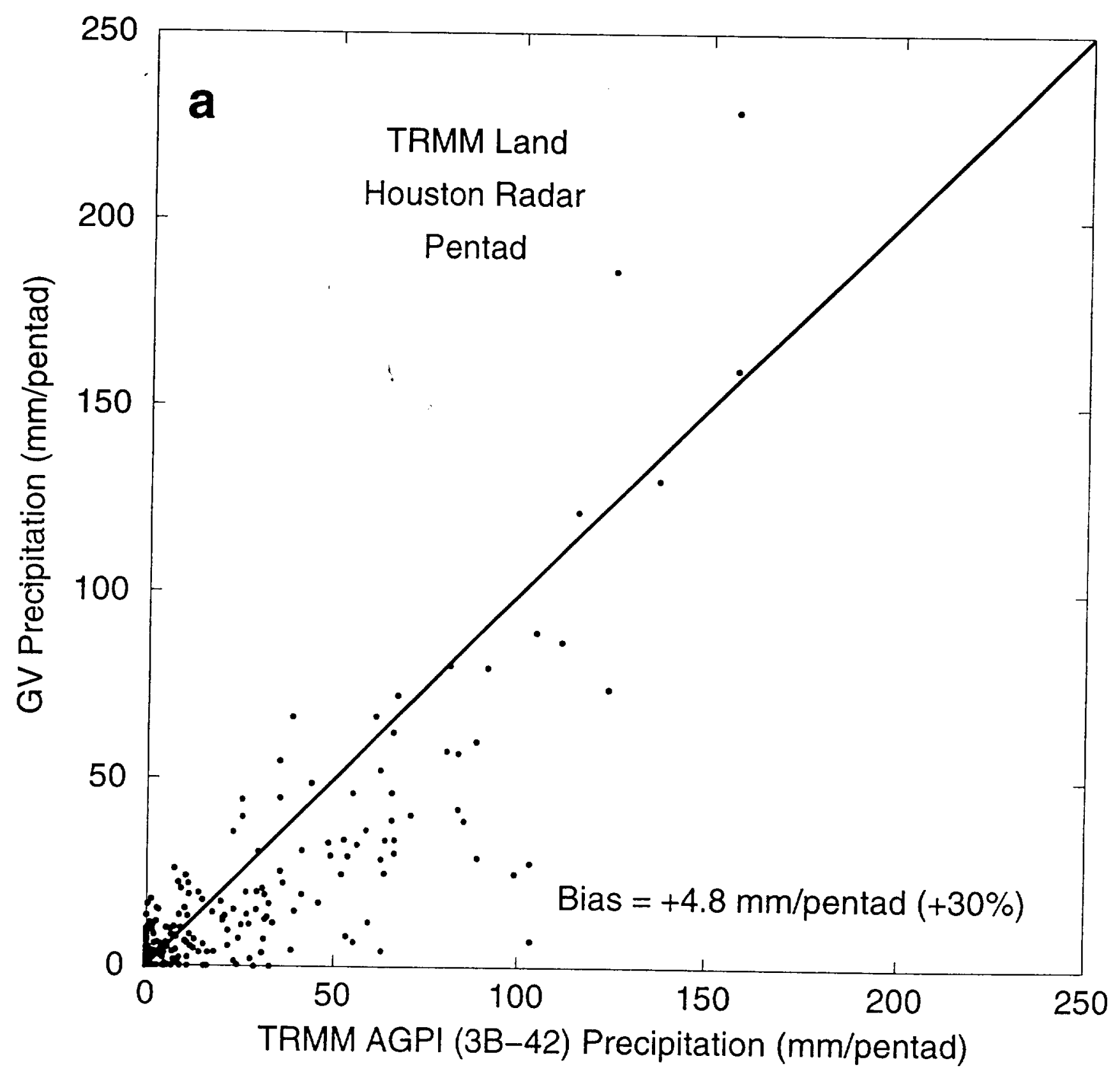

Figure 16a 


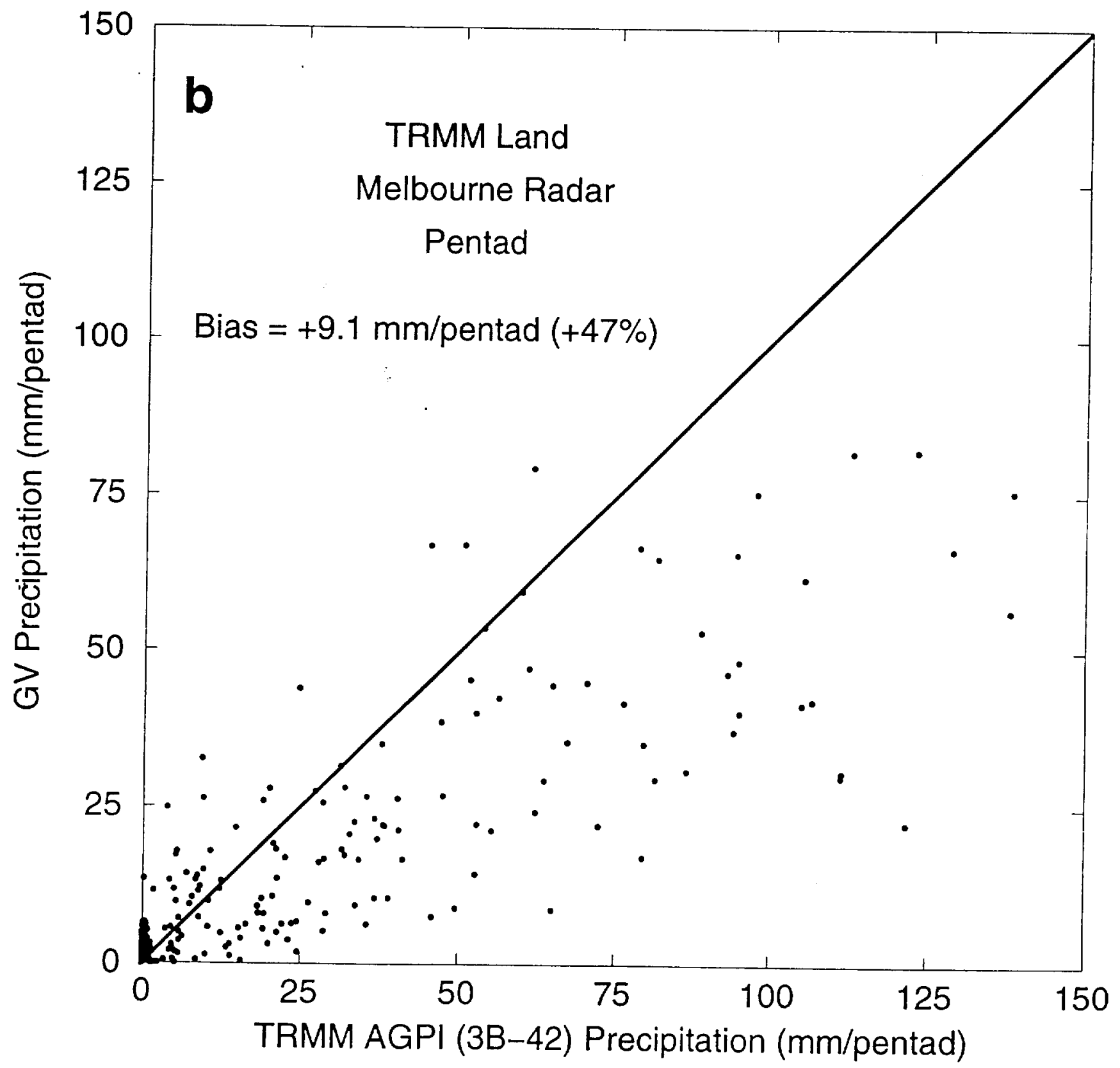

Figure 16b 


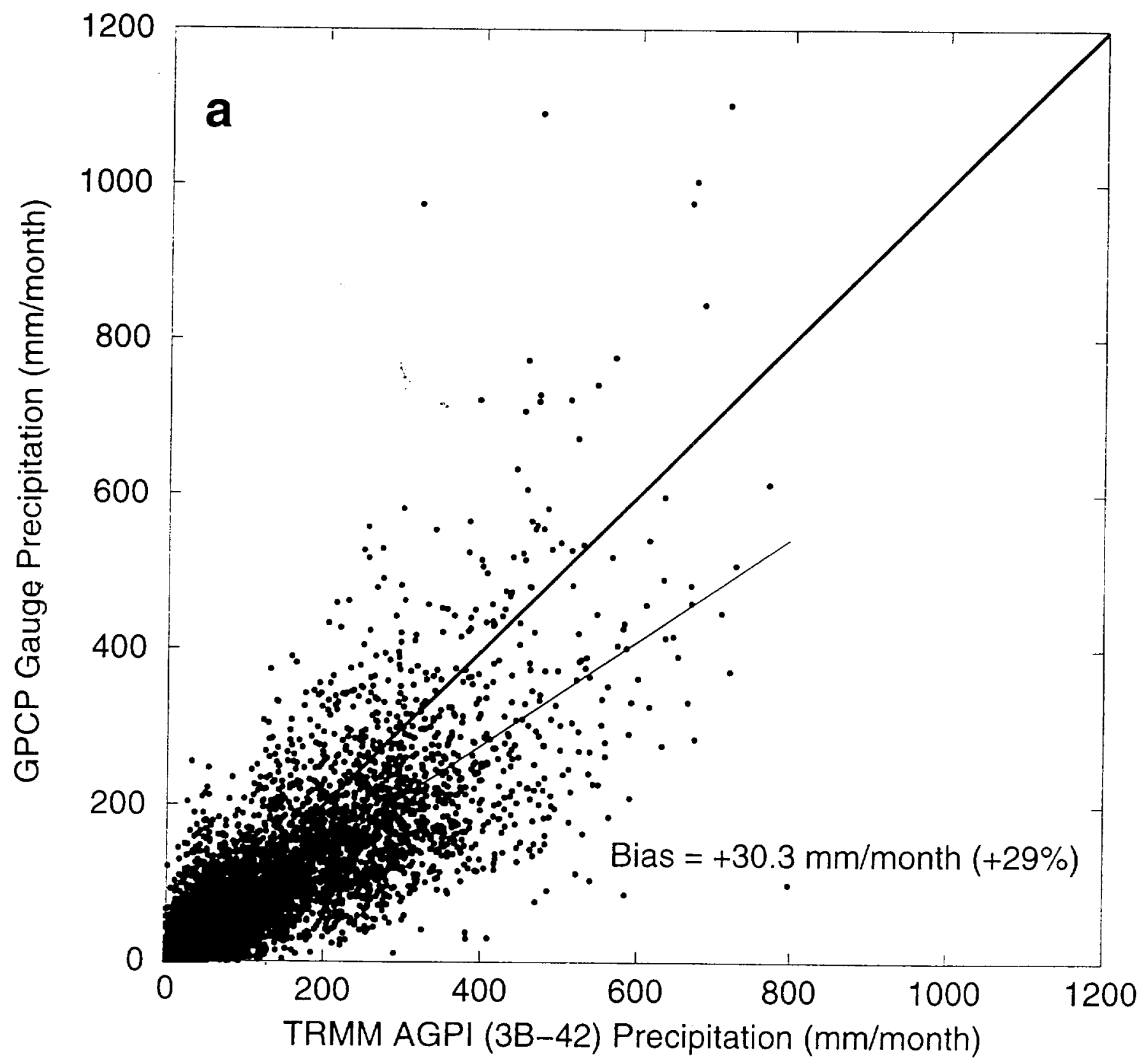

Figure 17a 


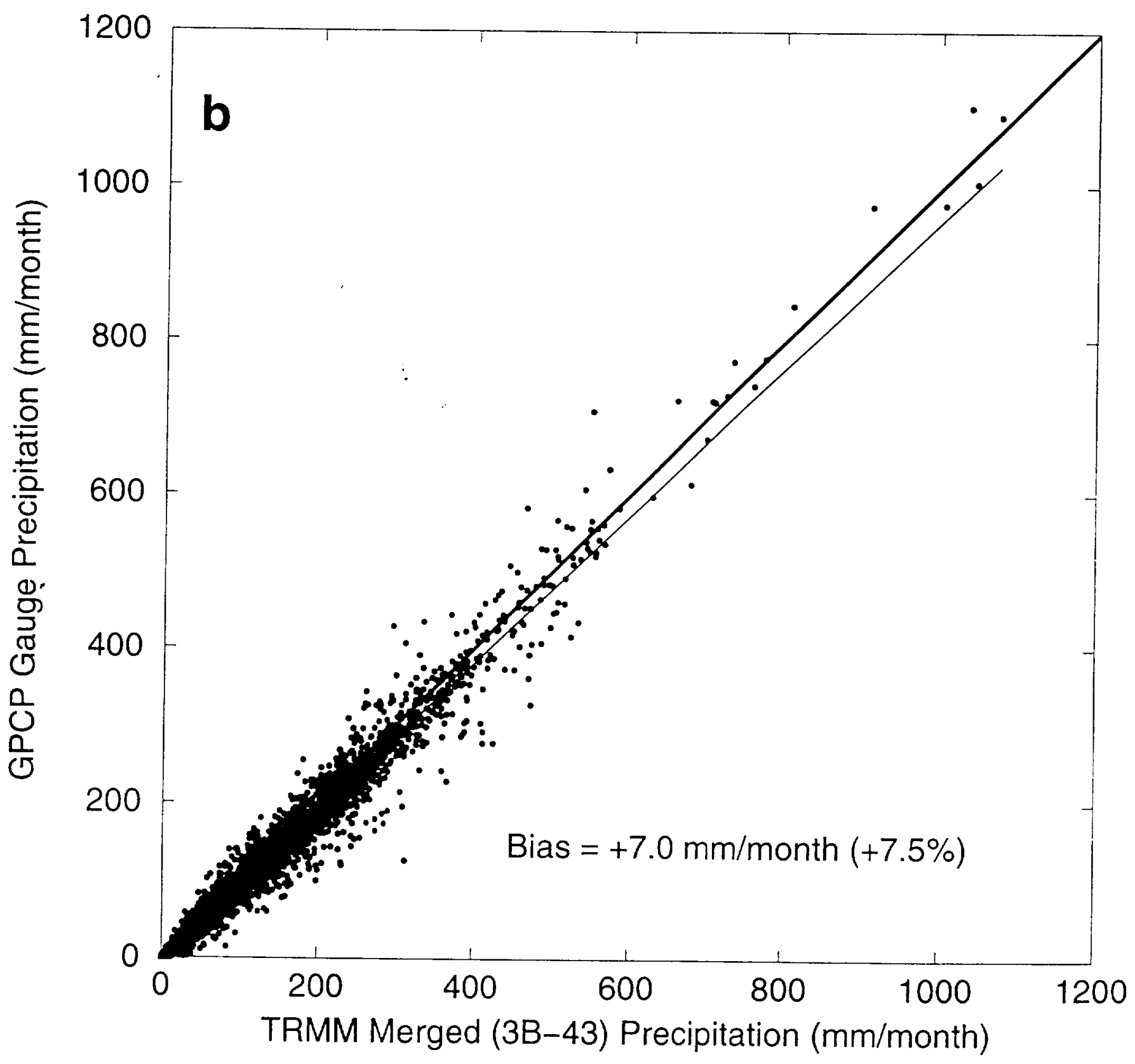

Figure $17 b$ 


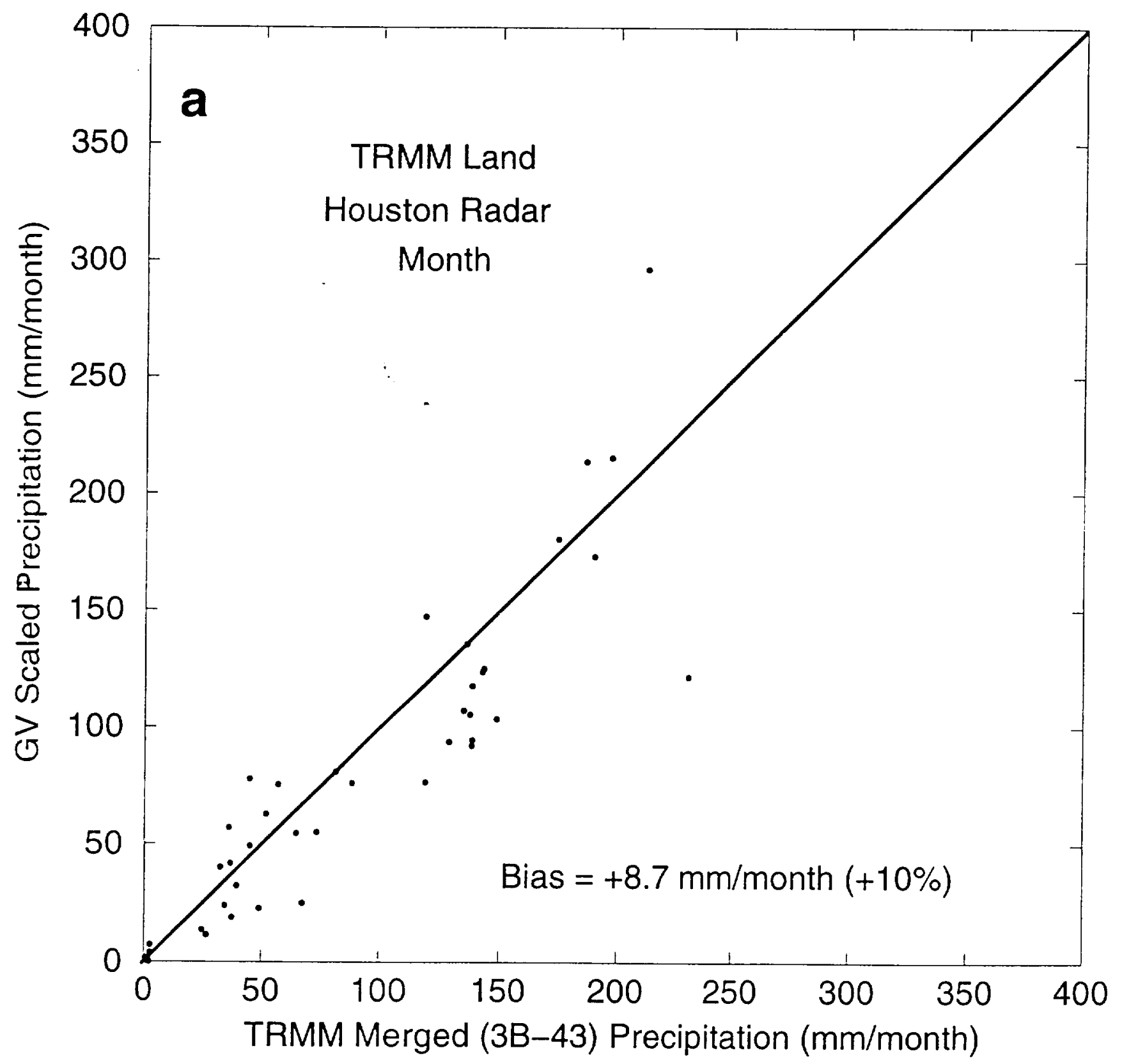

Figure 18a 


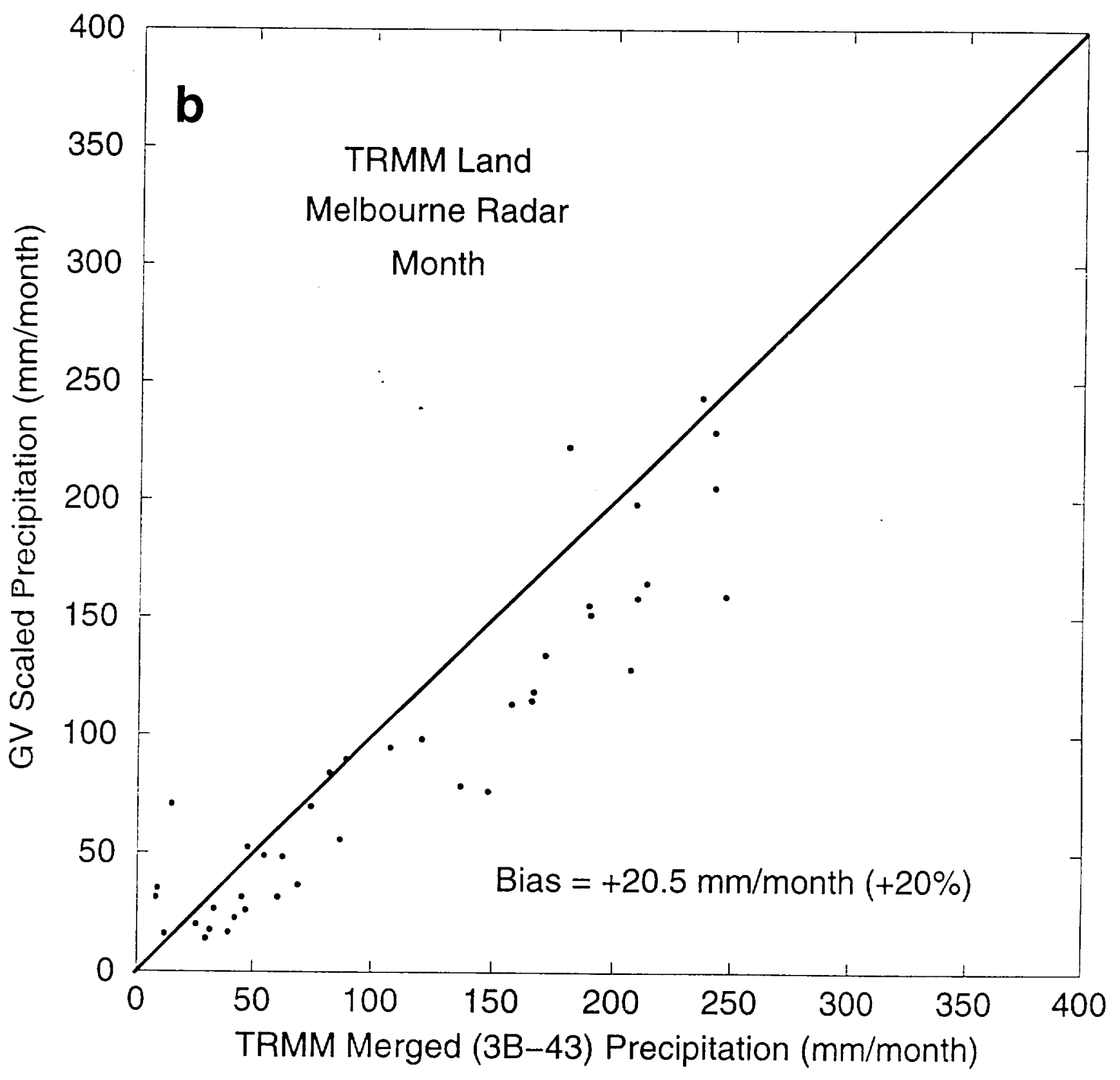

Figure $18 b$ 